\title{
THE GEVALTIG: AN INERTIAL FUSION POWERED MANNED SPACECRAFT DESIGN FOR OUTER SOLAR SYSTEM MISSIONS
}

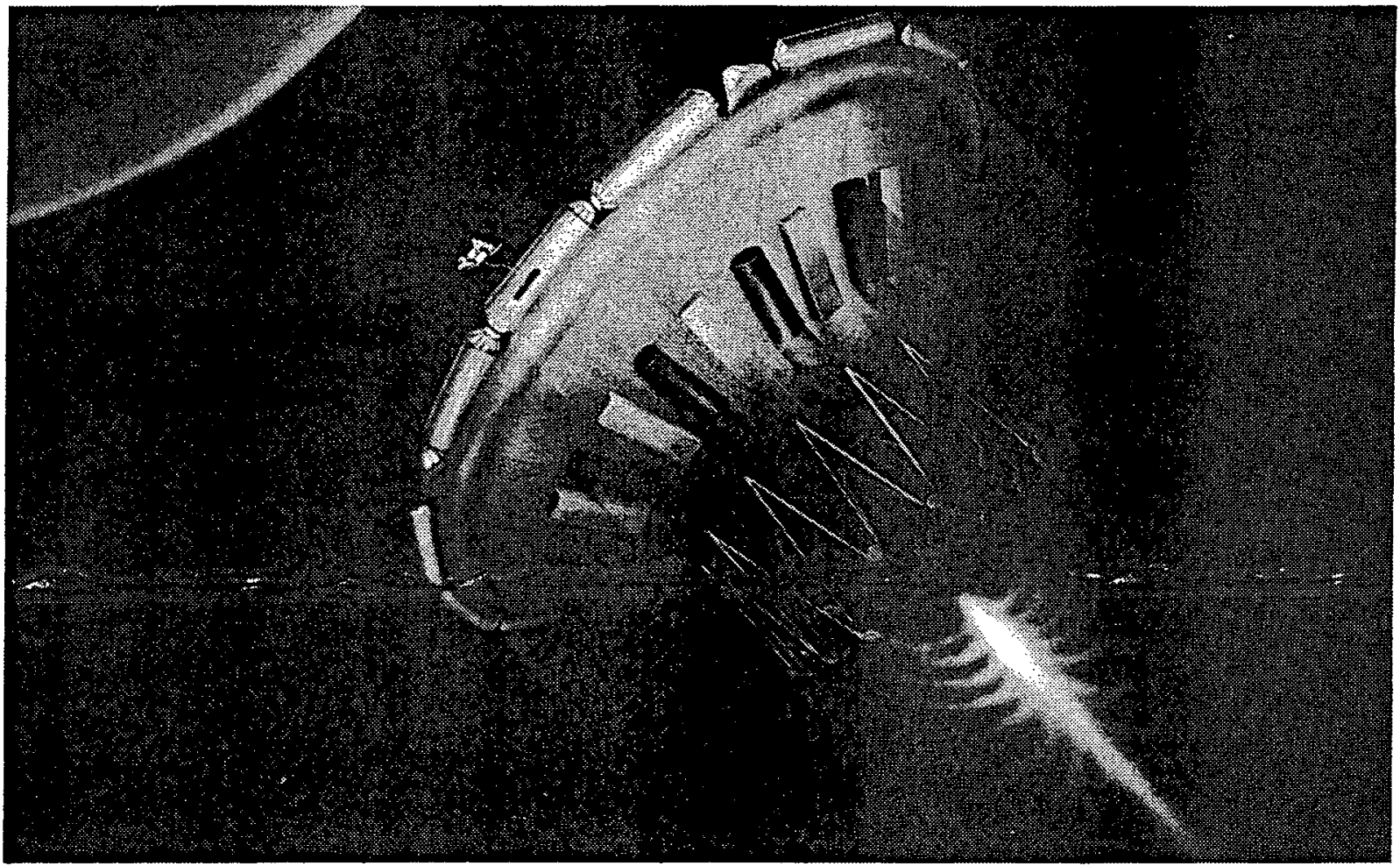

OCTOBER 1989

\section{DO NOT MICROFILM COVER}

Prepared for the

National Aeronautics and Space Administration

Lewis Research Center

by the

Energy Technology Engineering Center

Rocketdyne Division, Rockwell International

P. O. Box 1449, Canoga Park, CA 91304 


\section{DISCLAIMER}

This report was prepared as an account of work sponsored by an agency of the United States Government. Neither the United States Government nor any agency Thereof, nor any of their employees, makes any warranty, express or implied, or assumes any legal liability or responsibility for the accuracy, completeness, or usefulness of any information, apparatus, product, or process disclosed, or represents that its use would not infringe privately owned rights. Reference herein to any specific commercial product, process, or service by trade name, trademark, manufacturer, or otherwise does not necessarily constitute or imply its endorsement, recommendation, or favoring by the United States Government or any agency thereof. The views and opinions of authors expressed herein do not necessarily state or reflect those of the United States Government or any agency thereof. 


\section{DISCLAIMER}

Portions of this document may be illegible in electronic image products. Images are produced from the best available original document. 


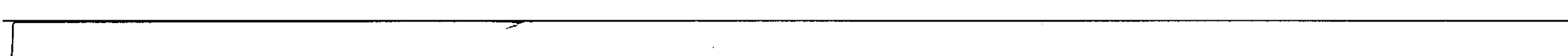




\section{DISCLAIMER}

This report was prepared as an account of work sponsored by an agency of the Untied States Government. Neither the United States Government or any agency thereof, nor their employees, makes any warranty, expressed or implied, or assumes any legal liability or responsibility for the accuracy, completeness, or usefulness of any information, apparatus, product or process disclosed, or represents that its use would not infringe privately owned rights. Reference herein to any specific commercial product, process, or service by trade name, trademark, manufacturer, or otherwise, does not necessarily constitute or imply its endorsement, recommendation, or favoring by the United States Government or any agency thereof. The views and opinions of authors expressed herein do not necessarily state or reflect those of the United States Government or any agency thereof.

Printed in the United States of America

Available from

National Technical Information Service

U.S. Department of Commerce

5285 Port Royal Road

Springfield, Virginia 22161 
NASA-CR-- 185163

DE90 002624

"THE GEVALTIG": AN INERTIAL

FUSION POWERED MANNED SPACECRAFT DESIGN

FOR OUTER SOLAR SYSTEM MISSIONS

OCTOBER 1989

Prepared for the National Aeronautics and Space Administration

Lewis Research Center

by

K. A. Murray

Energy Technology Engineering Center

Rocketdyne Division, Rockwe]1 International

P. 0. Box 1449, Canoga'Park', CA 91304

This dooument is

PUDLICLY RELHASA BL

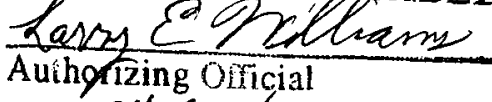

Date: $04 / 18 / 2007$

DISTREUTION OF THIS DOCUMENT IS UNLINITED 


\section{DISTRIBUTION}

ENERGY TECHNOLOGY ENGINEERING CENTER - INTERNAL

N. J. Hoffman

K. A. Murray

Library (10)

DISTRIBUTION (EXTERNAL):

NASA Scientific and Technical Information Facility (25)

Library - NASA Lewis Research Center

Report Control - NASA Lewis Research Center

Manager, DOE-SAN

Donald Schultz, NASA Lewis Research Center (23)

Patent Counse1, Rocketdyne Division, Rockwell International

Director, ETEC Project Office

DOE Technical Information Center (10)

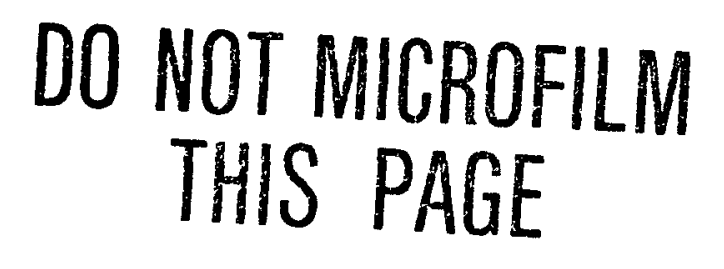




\section{SUMMARY}

The Gevaltig is an inertial fusion powered rocket engine capable of manned missions to other planets with round trip mission times as low as 100 days. An initial report by Orth et al (Reference 1) details the Gevaltig design for a manned mission to Mars. NASA-Lewis is performing a follow-on study to adapt the design to a mission to Titan, a moon of Saturn. This report documents work done by ETEC in support of the NASA-Lewis effort.

ETEC was contracted to perform four technical tasks: 1) Define component fixed masses and masses that vary with mission, 2) Interact with NASA-Lewis to define the optimum mission performance for the Titan mission, 3) Define the method for providing the electric power to start the inertial fusion rocket engine, and 4) Provide quarterly progress reports and a final report.

Within this final report, component masses are provided as a function of fuel pellet ignition frequency. These variable mass components include the fuel tanks, radiators, structure and EM pumps. Fixed mass components include the drivers, coil, coil shield, power processing system, payload, crew shield and laser mirrors. A nuclear reactor is included in the design for startup. This reactor provides $6 \mathrm{MW}$ of electrical power to thaw the liquid metal radiator coolants and to provide the energy for the first laser pulse.

Mission analysis was performed by NASA-Lewis. Various combinations of thrust, mission duration and specific impulse were evaluated to determine a reasonable mission scenario for the Titan mission. Calculations utilized component masses defined within this report. The mission analysis yielded several viable mission scenarios, with round trip durations of 370 to 500 days and initial (1aunch) masses from lunar orbit of 2500 to 20,000 metric tons. The mission that provides the lowest initial mass requires a 500 day round trip and an expellant pellet mass of 10 grams fired at a rate of 5 times per second. The mass breakdown includes 1400 metric tons of propellant, 1000 metric tons of power system mass, and 100 metric tons of payload, for a total of 2500 metric tons. A 370 day round trip is possible with a pellet mass of 20 grams, fired at a 30 $\mathrm{Hz}$ rep rate. The initial mass is 16,000 metric tons, including 13,000 metric tons of propellant. 


\section{ACKNOWLEDGEMENTS}

This study was funded by the NASA Lewis Research Center (LeRC). Mission analysis calculations and the results presented in Section VI were provided by John P. Riehl of NASA LeRC. The technical program manager at NASA LeRC is Donald F. Schultz.

Dr. Nathan J. Hoffman of the Energy Technology Engineering Center (ETEC) contributed his expertise throughout the study. 


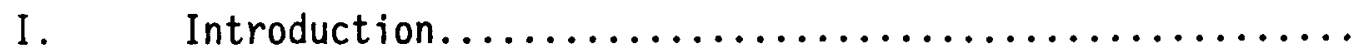

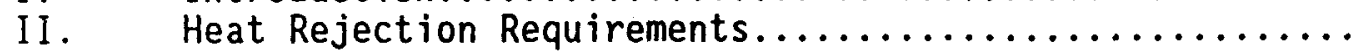

III. Component Masses for the Mars Mission.................

IV. Component Mass Results for the Titan Mission............

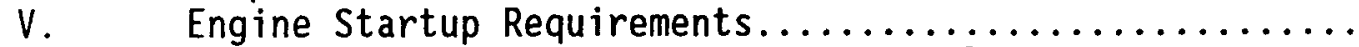

VI. Mission Analysis Methodology and Results..............

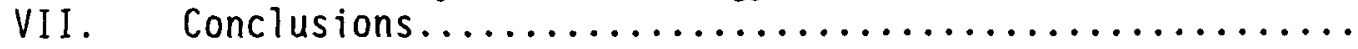

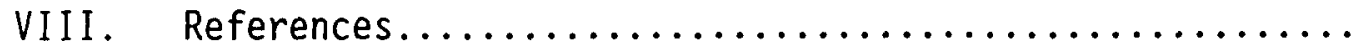

\section{$\underline{\text { TABLES }}$}

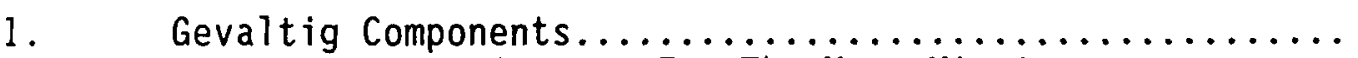

2. Component Mass Summary For The Mars Mission.............

3. Composition and Density of Radiator Materials...........

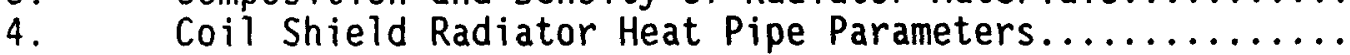

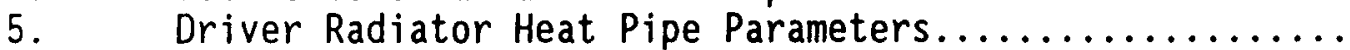

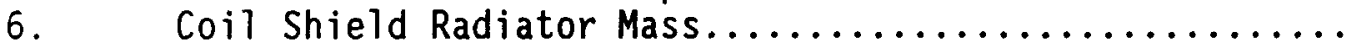

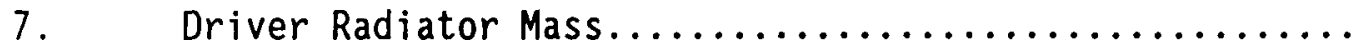

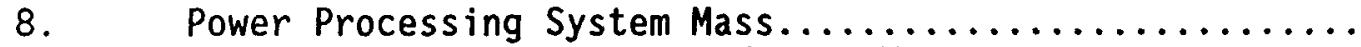

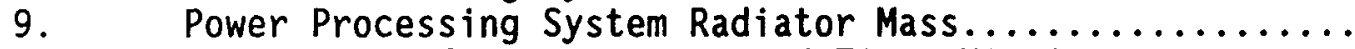

10. Comparison of Mars Mission and Titan Mission

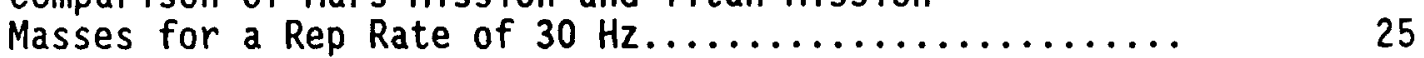

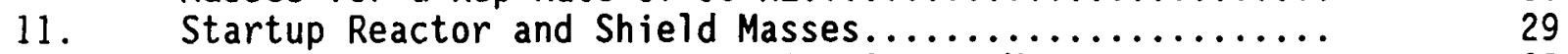

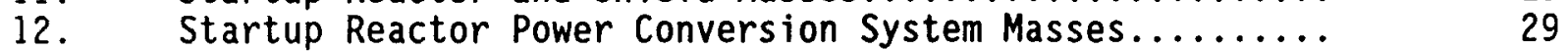

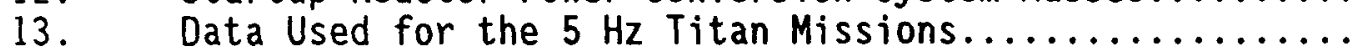

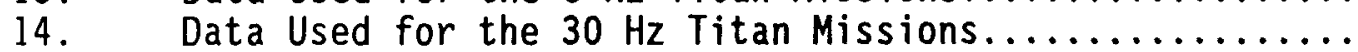

\section{FIGURES}

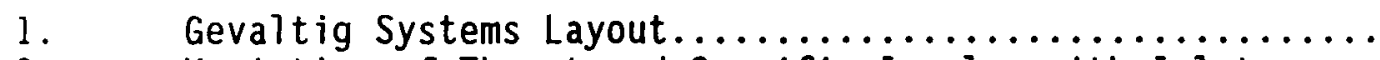

2. Variation of Thrust and Specific Impulse with Inlet

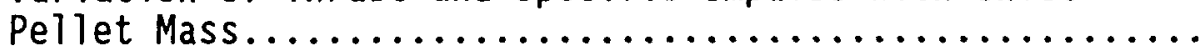

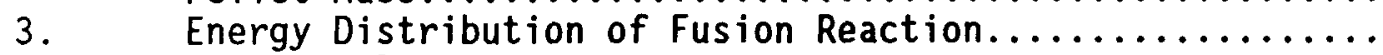

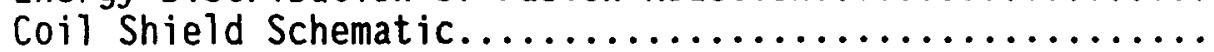

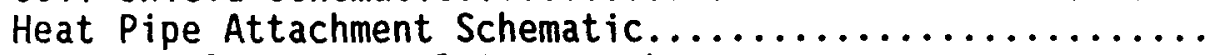

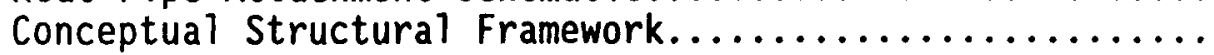

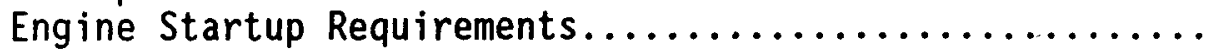

8. Power System Mass vs. Jet Power for Titan Mission.

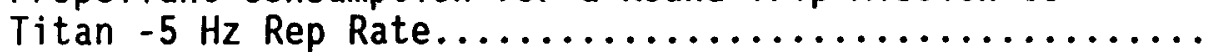

10. Launch Mass for a Round Trip Mission to Titan for

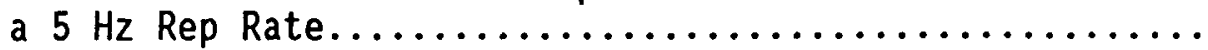

11. Propellant Consumption for a Round Trip Mission to

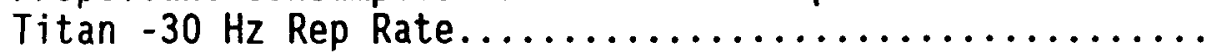




\section{FIGURES ... Cont.}

12. Launch Mass for a Round Trip Mission to Titan -

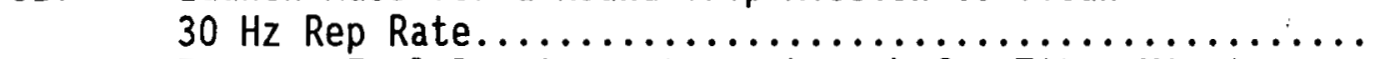

13. Tritium Fuel Requirements at Launch for Titan Mission.... 


\section{INTRODUCTION}

The Gevaltig is a manned interplanetary spacecraft design powered by inertial confinement fusion reactions. The fusion reactions provide a high specific impulse, allowing trip times that are significantly less than chemical or electric propulsion engines. A round trip mission to Mars with a crew of 10 people can be accomplished in as little as 100 days (Reference 1). An artist's conception of the rocket is shown in Figure 1 .

The Gevaltig rocket is powered by fusion microexplosions within a magnetic thrust chamber. A small pellet made of deuterium and tritium fuel (DT) with surrounding hydrogen expellant is centered in the chamber. KrF or other excimer laser drivers deposit a total of $5 \mathrm{MJ}$ of energy on the fuel pellet, causing ignition. The fusion energy gain (ratio of energy released to energy deposited by the drivers) is estimated to be 1500 , resulting in a total energy of $7500 \mathrm{MJ}$ from each microexplosion. The fusion reaction creates an expanding plasma of hot ions, which is diverted by the magnetic field generated from a single superconducting coil. The plasma exits the thrust chamber in the rearward direction, providing thrust. The frequency, or rep rate, at which fuel pellets are ignited is a variable to be determined by mission analysis. Rep rates in the range of one to tens of $\mathrm{Hz}$ are expected.

Energy from the fusion reaction is divided among plasma ions (debris), neutrons and $x$-rays. The neutron and $x$-ray emissions cannot be used for thrust and add to vehicle heating wherever they impinge on component surfaces. To minimize this heat gain, and to protect components from radiation damage, a conical design is dictated for the spacecraft (Reference 2). All components are placed along the cone in the shadow of the coil neutron shield. The half angle of the cone is $50^{\circ}$ to maximize jet efficiency. Heat pipe radiators make up the surface of the cone, radiating from both sides.

The Gevaltig was designed assuming the technology required for construction and launch will be available by A.D. 2020. The extrapolation of today's technology was applied to many of the components. Areas where technology development is required are shown in the table below. Smaller components (i.e. startup reactor) utilize near term technology.

\section{Component}

1. Fusion fuel pellets

2. Laser drivers

3. Superconducting coil

4. Power processing system

5. Radiators

\section{Technology Development Requirements}

gain, availability of tritium fuel

operating temperature, efficiency, lifetime

current density, material

efficiency, temperature of solid state equipment

fabricability, specific mass 


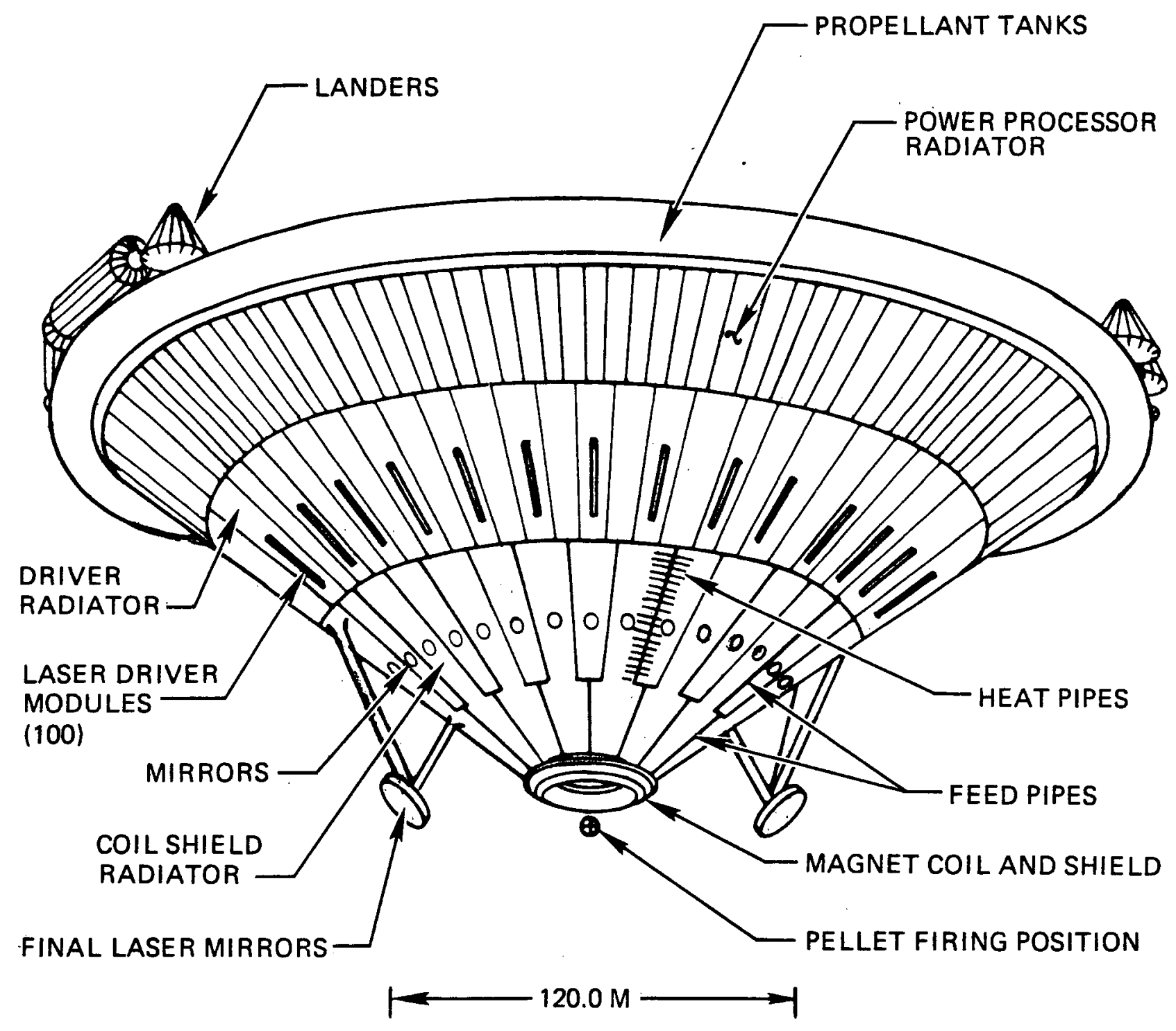

FIGURE 1. INERTIAL FUSION ROCKET SYSTEMS LAYOUT 
The Gevaltig can be adapted to other missions by varying the amount of expellant in the fuel pellet (DT fuel mass remains constant) and/or the frequency of fuel pellet detonation, or rep rate. Increasing the rep rate will directly increase the thrust of the engine. Increasing the pellet mass will also increase the thrust according to the square root of the pellet mass. Specific impulse, which is a measure of propellant thrust obtained per unit of propellant mass flow, decreases with increased pellet size because the energy is divided among a larger number of atoms. A graph showing how thrust and specific impulse vary with rep rate and pellet mass is shown in Figure 2 for the Gevaltig engine. The efficiency term in Figure 2 is the conversion efficiency of debris energy to momentum (approximately 60\%).

An increase in rep rate has the penalty of increasing the total heat rejection requirement of the power system, causing an increase in the total mass of the associated radiators. This increase in power system mass caused by the increase in power is an important parameter which indicates the technologically advanced state of the design.

The power system mass is a function of the jet power required to perform the mission. Power system masses calculated in this report are utilized in the mission analysis, in which the trip time and launch mass are determined. It is assumed that the Gevaltig will be constructed in low earth orbit (LEO) and boosted to a lunar orbit for departure. The lunar orbit departure precludes a radiation hazard to LEO inhabitants upon startup. 


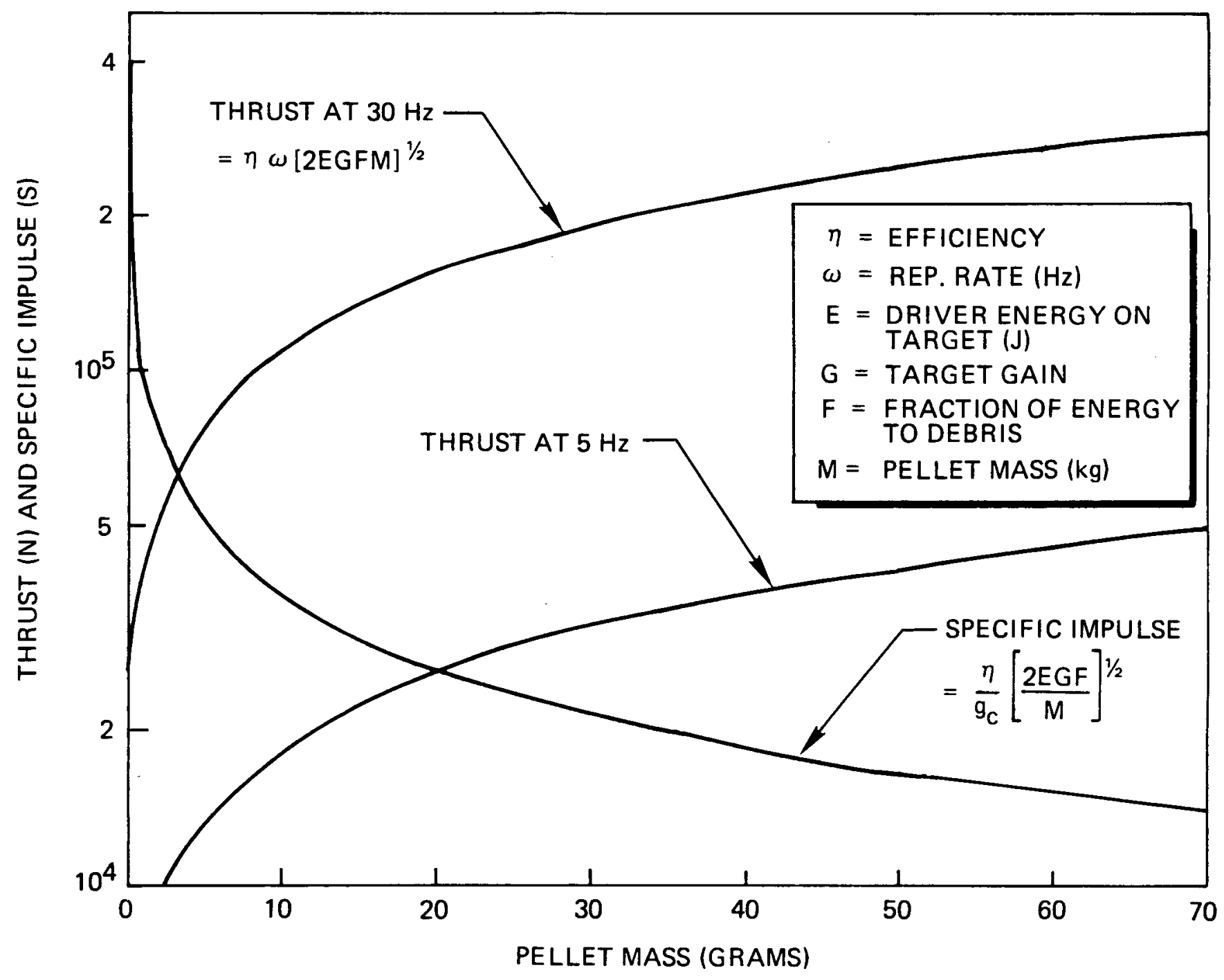

FIGURE 2. VARIATION OF THRUST AND SPECIFIC IMPULSE WITH PELLET MASS. 


\section{HEAT REJECTION REQUIREMENTS}

The frequency at which fuel pellets are ignited determines the heat rejection requirement of the spacecraft. The four major components requiring heat rejection are the coil shield, the laser driver modules (6\% efficient), power processing system (99\% efficient), and the laser mirrors.

The distribution of energy following the fusion reaction is shown in Figure 3. At an on-target energy of $5 \mathrm{MJ}$ and a gain of 1500, $7500 \mathrm{MJ}$ of energy are produced with each fusion microexplosion. Of this energy, $25 \%$ is deposited into the debris ions, $56 \%$ into neutrons, $12 \%$ into $x$-rays, and $7 \%$ into coup 1 ing 10 sses (assumed values). The neutrons and $x$-rays stream out in all directions from the microexplosion, and are not collimated by the magnetic coil. The coil shield subtends a solid angle of 3\% at the pellet, and thus absorbs $3 \%$ of the energy in the neutrons, $x$-rays and coupling losses in the form of heat. An additional $1 \%$ of the energy is absorbed into the laser mirrors.

The neutrons interacting with the lithium in the coil shield increase the coil neutron energy by a factor of 1.15 of the absorbed neutron energy. For a $30 \mathrm{~Hz}$ rep rate, a total of $5640 \mathrm{MW}$ of heat are absorbed into the coil shield and 1690 MW are absorbed into the laser mirrors, and must be radiated away from the structure.

Energy to fire the laser drivers is provided by an inductor pickup coil that is interior to the superconducting coil. An emf is generated when magnetic field lines compressed by the expanding plasma pass through the coil. The 6\% efficient laser drivers require $2500 \mathrm{MW}$ of input energy and have a waste heat rejection requirement of $2350 \mathrm{MW}$ at a $30 \mathrm{~Hz}$ rep rate. The power processing equipment is approximately $99 \%$ efficient, and has a waste heat rejection requirement of 33 MW at a $30 \mathrm{~Hz}$ rep rate. 
COIL SHIELD

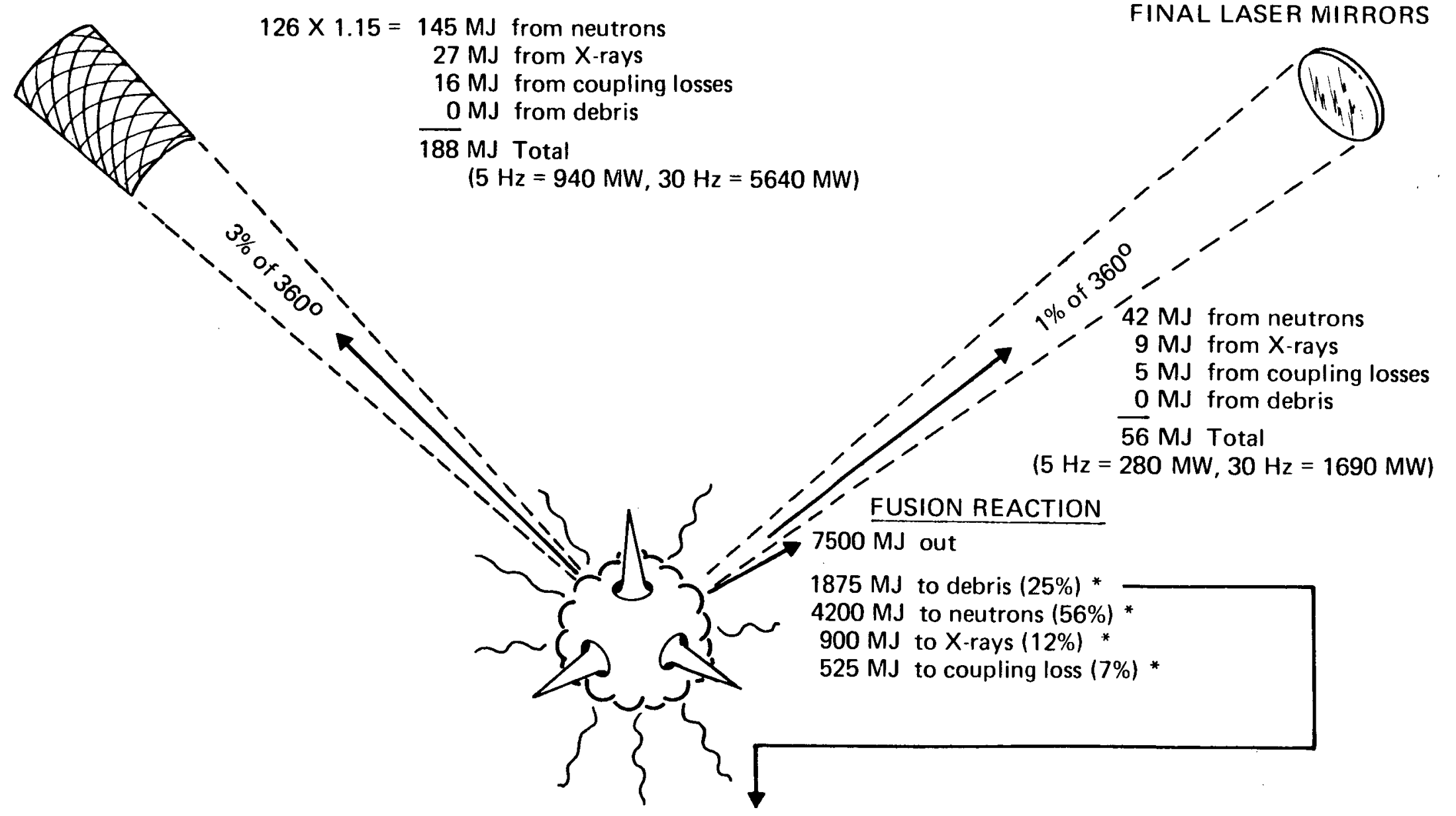

AT 36\% EFFICIENCY, 675 MJ OF DEBRIS ENERGY

PROVIDES JET POWER ( $\mathrm{Hz}=3375 \mathrm{MW}, 30 \mathrm{~Hz}=20.2 \mathrm{GW})$

* Assumed Values

87D-18-169

FIGURE 3. ENERGY DISTRIBUTION OF FUSION REACTION 


\section{COMPONENT MASSES FOR THE MARS MISSION}

A list of the components that make up the Gevaltig rocket are shown in Table 1. The weights that must vary with mission are noted, along with the reason for the weight variation (i.e., the crew shield weight increases with the crew module size, which in turn increases with the number of crew members.) Equations defining these masses for any rep rate or mission duration have been incorporated into a computer program. A summary of component masses for the Mars mission at rep rates of $5 \mathrm{~Hz}$ and $30 \mathrm{~Hz}$ is given in Table 2. A discussion of how these masses differ for the Titan mission is given in the next section.

\section{A. Fuel and Expellant}

About $44 \mathrm{mg}$ of DT fuel are needed to produce $7500 \mathrm{MW}$ of fusion output if the fusion burn is $50 \%$ efficient. The total amount of DT fuel required depends on the rep rate and the total thrust time, which is determined by the mission analysis. The hydrogen expellant weight is also determined by the mission analysis, and depends on the rep rate, the total thrust time, and the selected specific impulse. For the Mars mission (previously analyzed by JPL), approximately 4100 metric tons of propellant are required at a rep rate of 30 $\mathrm{Hz}$.

\section{B. Fuel Tanks}

Fuel tank weight is estimated to be $10 \%$ of the weight of the fuel plus expellant. Fuel tank weight can be defined only after mission analysis is performed and the mission duration is known. For the Mars mission, the tank weight is approximately 410 tons.

\section{Driver}

The laser driver has an estimated mass of 58 kilograms per kilojoule of input energy, with an additional 12 metric tons for the connecting trusses (Reference 3). Each of the 100 driver modules has an estimated length of $20-50 \mathrm{~m}$ and a cross-sectional area of $0.4 \mathrm{~m}^{2}$ (Reference 4). For an input energy of $50 \mathrm{~kJ}$ on the DT target for each module, the driver equipment has a total mass of 302 metric tons that does not vary with the mission. Additionally, the lasers are equipped with power conditioning equipment and waste heat radiators whose masses vary with rep rate and thus vary with the mission. These components will be discussed in paragraphs $E$ and $F$.

\section{Superconducting Coil and Coil Shield}

The superconducting coil must have a large enough magnetic field to counteract the force of the expanding plasma and to reverse the plasma expansion. This force, corresponding to the pressure of the plasma, dictates the cross-sectional area of the superconducting coil. A 12 Tesla magnetic field is required to stop and reverse the plasma expansion. Warm superconducting magnets (i.e., room temperature or higher) are assumed to be producable by $A D 2020$, so cooling of the magnet is not required. Foil type radiation shielding will be placed between the coil shield and the coil and prevent excess heating of the magnet. 


\section{TABLE 1}

\section{GEVALTIG COMPONENTS}

\section{COMPONENT}
A. Fuel \& Propellant
B. Fuel Tanks
C. Driver
D. Coil Shield and Coil
E. Coil Shield Radiator (1500K)
Driver Radiator (900K)

F. Power Processing System

G. Power Processing Radiator (373K)

\section{WEIGHT VARIABLE}

Distance and duration

of mission

yes

no

no

Amount of fuel and

propellant

On target energy

On target energy, gain,

Chamber geometry

yes

yes

no

yes

no

yes

yes

yes

no

no

no

no

Launchers

P. Coolant System for Pellet Launchers and Laser Mirrors
Fusion power

Driver power, efficiency and temperature

On target energy

Driver power and

power processing equipment efficiency

100 tons

Radiator size

Amount of fuel

Fusion power

No. of crew members

Startup requirements
N. Pellet factory

yes

Fusion power 
TABLE 2

COMPONENT MASS SUMMARY FOR THE MARS MISSION

\begin{tabular}{lcc} 
COMPONENT & $\begin{array}{c}\text { WEIGHT AT 5 HZ } \\
\text { (METRIC TONS) }\end{array}$ & $\begin{array}{c}\text { WEIGHT AT 30 HZ } \\
\text { (METRIC TONS) }\end{array}$ \\
\cline { 2 - 3 } Fuel Tanks & 70 & 410 \\
Driver & 300 & 300 \\
Driver Radiator & 30 & 290 \\
Coil Shield & 100 & 100 \\
Coil & 20 & 20 \\
Coil Shield Radiator & 15 & 210 \\
Power Processing System & 260 & 260 \\
Power Processor Radiator & 40 & 240 \\
Payload & 100 & 100 \\
Fuel Tank Refrig.System & 10 & 50 \\
Startup Reactor & 5 & 20 \\
Crew Shield & 140 & 140 \\
EM Pumps & 50 & 240 \\
Laser Mirrors & 10 & 10 \\
Laser Mirror Coolant System & 20 & 140 \\
Structure & 32 & 190 \\
Total Dry Mass & 1200 & 2720 \\
& & \\
\cline { 2 - 2 } & &
\end{tabular}


Recently developed superconducting materials have a current density of approximately $100,000 \mathrm{amps} / \mathrm{cm}^{2}$. Advanced technology superconducting materials (A.D.2020) are estimated to have a current density of $300,000 \mathrm{amps} / \mathrm{cm}^{2}$. From the projected current density and the magnetic field requirement, the required crosssectional area of the coil was found to be approximately $900 \mathrm{~cm}^{2}$. The density was found by assuming the coil windings are made of $8 / 9$ th superconducting material, and $1 / 9$ th copper.

The resulting mass of the Gevaltig coil is approximately 20 metric tons and does not vary with mission.

The coil shield is placed in front of the magnet to absorb neutrons and to prevent heating of the coil. The radius of both the coil and the coil shield are dictated by the distance of the shield from the point of microexplosion. Placement of the shield $15 \mathrm{~m}$ away along the cone reduces the energy deposition in the first wall below the value of $35 \mathrm{MJ} / \mathrm{kg}$, to avoid vaporization of the carbon in the shield material. The coil shield must be wide enough to protect the superconducting coil from damage by neutrons and $x$-rays. To allow for edge effects, the coil shield must intercept about $3 \%$ of the pellet neutrons and $x$ rays. A thickness of $1.5 \mathrm{~m}$ is required to prevent neutrons from penetrating the superconducting coil. The resulting coil shield has a radius of $11.5 \mathrm{~m}$, and a mass of 100 metric tons. A schematic of the coil shield is shown in Figure 4. Because the energy released in each micro-explosion is constant $(7500 \mathrm{MJ})$, the coil weight and coil shield weight will not vary with mission.

\section{E. Coil Shield Radiator and Driver Radiator}

\section{Radiator Configuration}

As shown in Figure 1, the coil shield radiator is located near the apex of the cone, adjacent to the coil shield. EM pumps force lithium coolant through the coil shield and feed pipes. The walls of each feed pipe are penetrated by heat pipes, so that direct contact heat transfer is provided, in a configuration similar to one proposed by Lawrence Livermore National Laboratory (Reference 5). The penetrations into the feed pipes are staggered, to allow full radiator surface coverage by heat pipes. Each heat pipe operates independently. A schematic of the heat pipe attachments is shown in Figure 5 . The heat pipes contain a lithium working fluid, and radiate at an average temperature of $1500 \mathrm{~K}$. Both the coil shield and the coil shield radiator are made of Astar 811C, a tantalum based refractory alloy. Composition and density are given in Table 3.

IABLE 3

COMPOSITION AND DENSITY OF RADIATOR MATERIALS

DENSITY
$\left(\mathrm{kg} / \mathrm{m}^{3}\right)$$\quad \begin{aligned} & \text { COMPOSITION } \\ & (\mathrm{w} / \mathrm{0})\end{aligned}$

Astar 811C $\quad 16,700 \quad 90.3 \mathrm{Ta}, 8.0 \mathrm{~W}, 0.7 \mathrm{Re}, 1.0 \mathrm{Hf}$, $\mathrm{Nb}-1 \mathrm{Zr} \quad 8,400 \quad 99 \mathrm{Nb}, 1.0 \mathrm{Zr}$ 


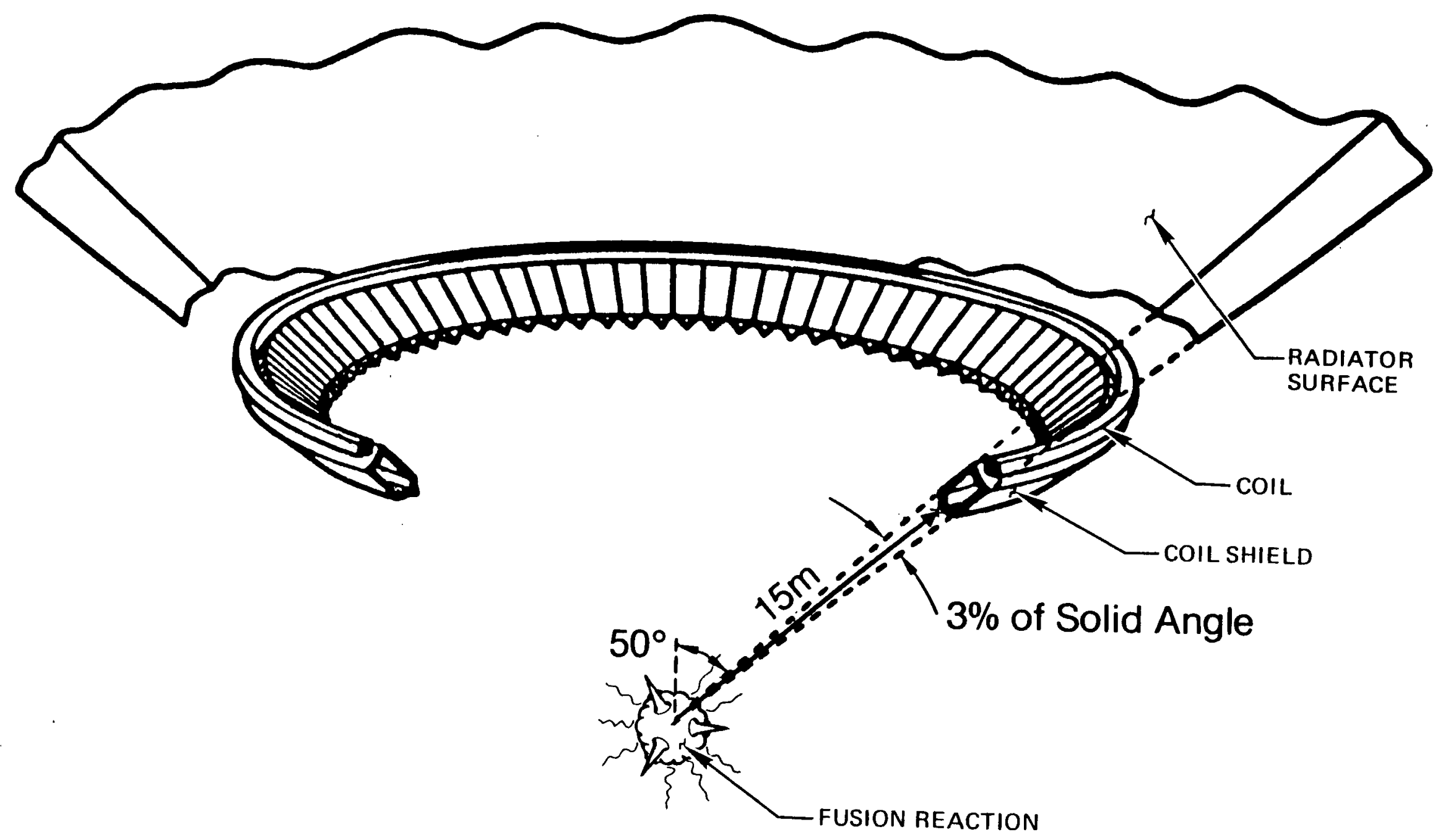

FIGURE 4. COIL SHIELD SCHEMATIC 
FIGURE 5

HEAT PIPE ATTACHMENT SCHEMATIC

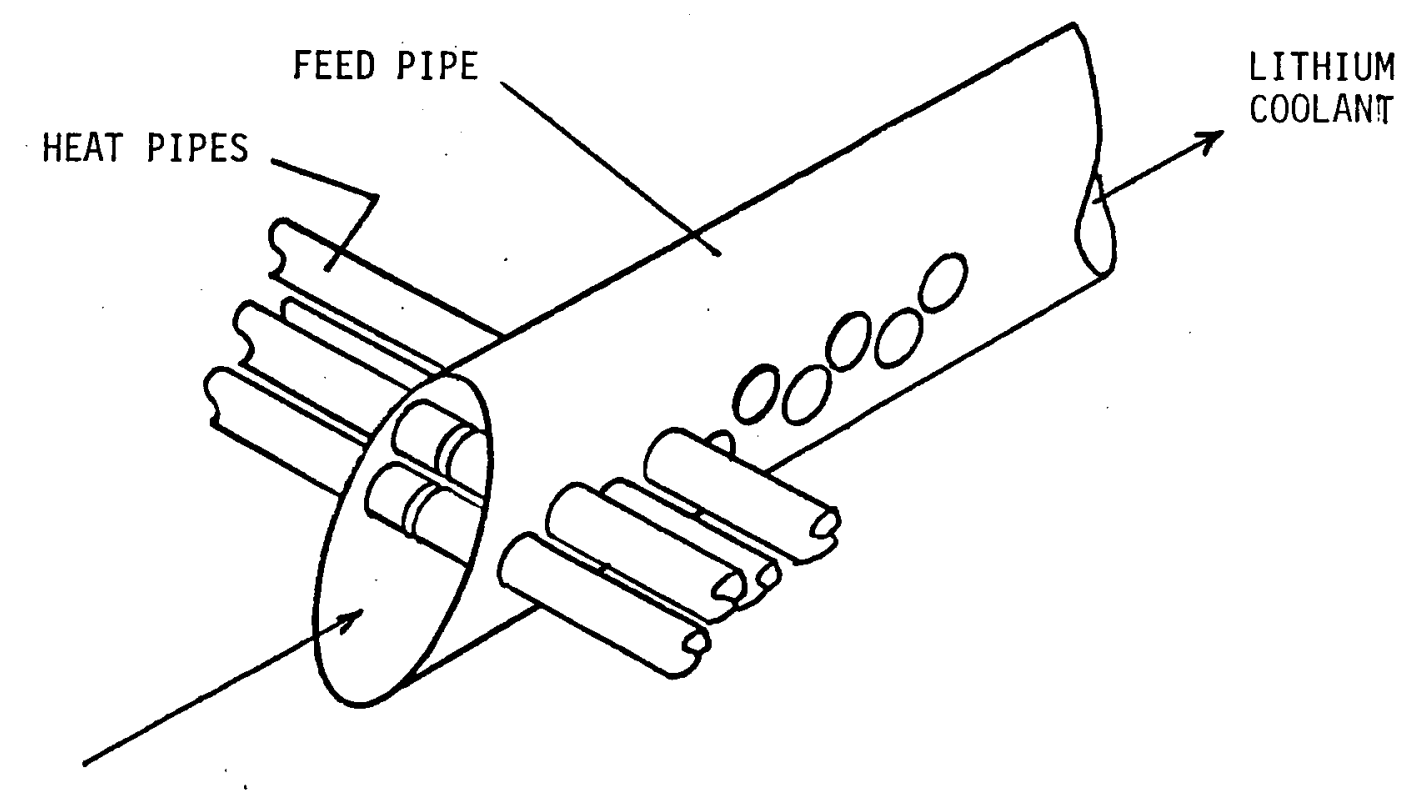


The driver radiator is located further out on the cone. Feed pipes carry sodium coolant from the 100 driver modules to heat pipes in a configuration similar to the coil shield radiator. The drivers operate at $1000 \mathrm{~K}$, and the heat pipes radiate at an average temperature of 900K. Both the feed pipes and the heat pipes of the driver radiator are made of $\mathrm{Nb}-1 \mathrm{Zr}$ material.

Because the radiators are conical in shape, only a portion of the radiant energy emitted from the inside of the cone will be absorbed by deep space, with the remainder intercepted by other parts of the cone. Configuration or view factors for conical geometries have been derived (Reference 6). The net exchange coefficient $(F)$ between the inside of the coil shield radiator and deep space is 0.71 , and the exchange coefficient between the inside of the driver radiator and deep space is 0.51 .

The total surface area of each radiator can be found by utilizing the radiation heat transfer correlation (assumes deep space is zero Kelvin):

$$
A=Q S /\left(F_{i}+F_{0}\right) \sigma T^{4}
$$

where $Q$ is the amount of energy transferred, $S$ is the safety factor to allow for damage of a percentage of the heat pipes, $F_{j}$ and $F_{0}$ are the exchange coefficients to deep space from the inside and outside surface areas of the radiator, respectively. The outside surface area has a configuration factor of 1.0 and thus $F$ is equal to the surface emissivity. An emissivity of 0.9 was assumed for both the coil shield and driver radiators.

For a rep rate of $30 \mathrm{~Hz}$ and a safety factor of 1.1 , the resulting cone segment length is $58.6 \mathrm{~m}$ for the coil shield radiator and $85.7 \mathrm{~m}$ for the laser radiator.

\section{Segmented Heat Pipe Concept}

The heat pipe radiator design is an advanced design in that it does not rely on armor for protection from micrometeoroid penetration. Armored radiators are traditionally heavy. To reduce the specific mass, heat pipes are segmented to allow thin-walled construction $(0.05 \mathrm{~mm})$. In addition, bumpers are utilized to protect the feed pipes, so the pipes themselves do not have to be armored.

Experiments in refractory metal research have shown that interaction with liquid metal causes mass transfer of the material at a rate of less than $.005 \mathrm{~mm} / \mathrm{yr}$. This is less than one tenth of the proposed wall thickness. The most common failure mechanism is due to highly localized redeposition of material. This may cause partial plugging of an artery or wick. As long as all arteries are not plugged, the heat pipe remains operational.

The membrane heat pipe concept was originally. considered for this design. This concept is based on the assumption that penetration of a pipe by a micrometeoroid does not result in automatic loss of the heat pipe (Reference 7). The heat pipe is not lost unless the penetration is large enough to cause leakage of the working fluid. If the surface tension of the fluid is sufficient to keep the fluid from leaking out through the penetration, then the heat pipe is assumed to remain functional in spite of the micrometeoroid penetration. However, it 
was found that for the wall thickness selected, a meteoroid capable of penetrating the wall causes a hole size four times larger than the meteoroid diameter (Reference 8), which is larger than the maximum size capable of retaining the working fluid by surface tension. As a result, either an armored design or segmentation of heat pipes is required.

The amount of segmentation of heat pipes required was determined by first choosing a wall thickness, and then subdividing the radiator into heat pipes with surface areas small enough to have a $90 \%$ survivability from micrometerorid penetration. To accommodate losses, a spare heat pipe array covering $10 \%$ additional surface area is included. A $90 \%$ radiator reliability does not necessarily result in an optimum system mass, but was chosen as a basis for the design.

The mass of incipient particle able to penetrate the heat pipe wall was found using established penetration relations (Reference 9). The flux of particles of penetration mass or greater was then found by utilizing the NASA simplified cometary meteoroid model (Reference 10). The results presented here are for a transfer orbit between 1.0 AU and 1.5 AU (Earth to Mars transfer). For missions to the outer planets, the cometary meteoroid flux decreases, but asteroidal meteoroids must be taken into account. Also, Saturn's rings pose a meteoroid hazard. As a result, missions to the outer planets may require a slightly modified radiator design, or a trajectory that extends out of the plane of the ecliptic.

The maximum surface area $A$ into which the heat pipes must be fractionated to increase their survivability to $90 \%$ can be found by the following equation:

$$
A=-\ln P(n=0) /(N, t)
$$

Where $P(n=0)$ is the probability of no lethal impacts on a given component, $N$, is the lethal particle flux (found from the NASA model) in particles $/ \mathrm{m}^{2}-\mathrm{s}$, and $t$ is the mission lifetime in seconds (Reference 9). For a $90 \%$ probability of no lethal impacts and a mission lifetime of 100 days, the surface area of each heat pipe in the coil shield radiator is $.013 \mathrm{~m}^{2}$, and the surface area of each driver radiator heat pipe is $0.0075 \mathrm{~m}^{2}$.

The radiator surface area and the individual heat pipe surface areas dictate the number of heat pipes making up the radiator. The radius of each heat pipe should be minimized so that the length can be maximized to reduce the number of feed pipes required. This results in a minimum radiator weight. However, the heat pipe diameter is constrained by the allowable vapor pressure drop. In order for the heat pipe to remain isothermal along its length, the vapor pressure drop through the pipe must remain low. The minimum radius for a pressure drop resulting in a 20K temperature decrease in the lithium heat pipes and a $10 \mathrm{~K}$ temperature decrease in the sodium heat pipes was calculated. The vapor velocity was then checked against the sonic limit. In both cases, the vapor velocity is less than $20 \%$ of the sonic vapor velocity. The resulting dimensions are given in Tables 4 and 5 for the coil shield radiator and the laser radiator for rep rates of 5 and $30 \mathrm{~Hz}$. 


\section{TABLE 4}

\section{COIL SHIELD RADIATOR HEAT PIPE PARAMETERS}

\begin{tabular}{lll} 
& $5 \mathrm{~Hz}$ & $\underline{30 \mathrm{~Hz}}$ \\
\cline { 2 - 3 } Heat Load (W) & $9.4 \times 10^{8}$ & $5.64 \times 10^{9}$ \\
Radiating Temperature (K) & 1500 & 1500 \\
Surface Area (m²) & 2200 & 13,400 \\
No of Heat Pipes & 541,000 & $3,250,000$ \\
Heat Pipe Length (m) & 1.0 & 1.0 \\
Heat Pipe Diameter (m) & 0.002 & 0.002
\end{tabular}

TABLE 5

DRIVER RADIATOR HEAT PIPE PARAMETERS

$\underline{5 \mathrm{~Hz}}$

$30 \mathrm{~Hz}$

Heat Load (W)

Radiating Temperature (K)

Surface Area $\left(\mathrm{m}^{2}\right)$

No of Heat Pipes

Heat Pipe Length (m)

Heat Pipe Diameter (m)
$3.9 \times 10^{8}$

900

8200

$3,440,000$

0.30

0.008
$2.35 \times 10^{9}$

900

49,200

$20,600,000$

0.30

0.008

The evaporator section of each heat pipe is short in length compared to the condensing section, and is contained within the feed pipes. A $25 \mathrm{C}$ temperature drop across the wall results in an evaporator section length of $.02 \mathrm{~m}$ for the coil shield radiator and $0.002 \mathrm{~m}$ for the driver radiator.

\section{Radiator Mass}

The minimum fabricability thickness for Astar $811 \mathrm{C}$ and $\mathrm{Nb}-1 \mathrm{Zr}$ is estimated to be $0.05 \mathrm{~mm}$. This estimate is based upon an earlier design of heat pipe radiators (Reference 11).

The liquid inventory of an arterial heat pipe can be calculated by sizing the arteries to cause a pressure drop that is less than the capillary pumping pressure provided in the wick. Large diameter arteries have a small pressure drop, but also have a larger mass of lithium than small arteries. The minimum 
artery size is one that creates a pressure drop that, when combined with the vapor pressure drop, is slightly less than the capillary pumping pressure. The liquid-filled wick (including the liquid in the arteries) was found to be less than $10 \%$ of the wall mass. The wicking material is assumed to be $90 \%$ porous (liquid filled).

The feed pipes are separated by a distance equal to twice the average length of the heat pipes, so that coolant can be carried to all heat pipes. The coil shield radiator includes 64 feed pipes, $1.4 \mathrm{~m}$ apart, extending outward from the coil shield. When the circumference of the radiator doubles (about $18 \mathrm{~m}$ along the cone surface from the shield), each pipe splits into two, maintaining the same distance between pipes. The number of feed pipes in the driver radiator depends on the engine rep rate. For a rep rate of $30 \mathrm{~Hz}$, the driver radiator includes 900 feed pipes, $0.6 \mathrm{~m}$ apart (average) connected to the $100 \mathrm{driver}$ modules via a manifold.

The diameter of the feed pipes is found by assuming a temperature increase of $200^{\circ} \mathrm{C}$ inside the shield and driver modules and a velocity of $6 \mathrm{~m} / \mathrm{s}$ in the pipes. The total cross sectional area of the feed pipes is given by:

$$
A=Q / \rho C_{p}-T V
$$

where $Q$ is the heat transferred, $\rho$ is the liquid density, $c_{p}$ is the heat capacity of the coolant, $\Delta \mathrm{T}$ is the temperature increase inside the shield or driver module, and $v$ is the velocity of coolant inside the feed pipes. When the coil shield feed pipes split after $18 \mathrm{~m}$ of length, the total cross-sectional area stays the same, decreasing the feed pipe diameter.

The feed pipe thickness is sized to accommodate internal pressure. For a $30 \mathrm{~Hz}$ rep rate, the coil shield radiator feed pipes, made of Astar $811 \mathrm{C}$, have a diameter of $0.24 \mathrm{~m}\left(\mathrm{~g}^{\prime \prime}\right)$ and are $0.3 \mathrm{~mm}$ thick. The $\mathrm{Nb}-1 \mathrm{Zr}$ driver radiator feed pipes have a diameter of $0.05 \mathrm{~m} \mathrm{(2")} \mathrm{and} \mathrm{are} 0.5 \mathrm{~mm}$ thick. In order to protect the feed pipes from micrometeoroid damage, a protective bumper will be installed around the pipes. This bumper consists of a very thin sheet of metal surrounding each pipe at a slightly larger radius. When a meteoroid impact occurs, the bumper is penetrated, but the collision causes the brittle meteoroid to shatter. For relative velocities of $20 \mathrm{~km} / \mathrm{s}$ (average velocity of extraterrestrial meteoroids), the incident particle may be completely vaporized by the bumper and the probability of damaging the protective surface falls off rapidly with distance between the bumper and the surface. Thus, a very thin bumper can act as a shield to a surface needing protection. A separation distance equal to 20 times the incipient particle diameter (about $5 \mathrm{~mm}$ ) has been found to be sufficient in many cases (Reference 9). A bumper thickness of $.05 \mathrm{~mm}$ was calculated based on equating the $\mathrm{g} / \mathrm{cm}^{2}$ of the bumper material to the $\mathrm{g} / \mathrm{cm}^{2}$ of the largest particle to be stopped in order to increase the survivability of each feed pipe to $99 \%$. 
Tables 6 and 7 summarize the weight characteristics of the coil shield radiator and the driver radiator. The total mass of the coil shield radiator is 200 metric tons $(.036 \mathrm{~kg} / \mathrm{kW})$ for $30 \mathrm{~Hz}$ and 14 metric tons $(.015 \mathrm{~kg} / \mathrm{kW})$ for the $5 \mathrm{~Hz}$ case. The mass of the driver radiator is 268 metric tons $(0.11 \mathrm{~kg} / \mathrm{kW})$ for $30 \mathrm{~Hz}$ and 24 metric tons $(.062 \mathrm{~kg} / \mathrm{kW})$ for the $5 \mathrm{~Hz}$ case.

\begin{tabular}{lcr}
\hline & \multicolumn{1}{c}{ TABLE 6 } \\
& COIL SHIELD RADIATOR MASS & \\
& $\underline{5 \mathrm{~Hz}}$ & $\underline{30 \mathrm{~Hz}}$ \\
Heat Pipe Mass (kg) & 6700 & 40,100 \\
Feed Pipe Mass (kg) & 800 & 24,000 \\
Coolant Mass (kg) & 6500 & 132,200 \\
Bumper Mass (kg) & 400 & 4,300 \\
Total Mass (kg) & 14,400 & 200,600 \\
Specific Mass (kg/kW) & 0.015 & 0.036 \\
& & \\
\hline
\end{tabular}

TABLE 7

DRIVER RADIATOR MASS

$\underline{5 \mathrm{~Hz}} \quad \underline{30 \mathrm{~Hz}}$

Heat Pipe Mass $(\mathrm{kg})$

Feed Pipe Mass $(\mathrm{kg})$

Coolant Mass $(\mathrm{kg})$

Bumper Mass $(\mathrm{kg})$

Total Mass $(\mathrm{kg})$

Specific Mass $(\mathrm{kg} / \mathrm{kW})$

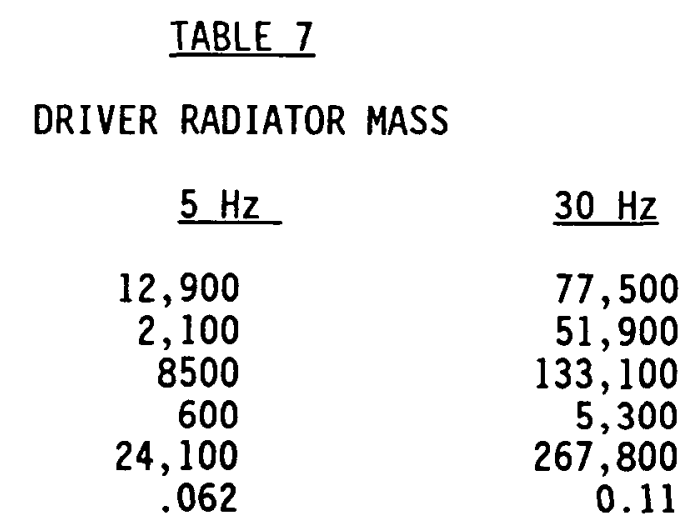

For both radiators, the heat pipe mass is directly proportional to the rep rate. The feed pipe, bumper, and coolant masses are approximately proportional to the rep rate to the 1.5 power because the masses increase with both length and diameter of feed pipe. The ratio of coil shield radiator specific mass to driver radiator specific mass is proportional to twice the radiating temperature ratio to the fourth power, because the density of Astar 811C is approximately twice that of $\mathrm{Nb}-1 \mathrm{Zr}$.

The thin-walled arrays of heat pipes and feed pipes are not expected to provide structural support of the spacecraft. A structural framework, consisting of support trusses and lateral support rings, is also included in the component mass summary. 


\section{F. Power Processing System}

The power supply to the laser drivers is provided by an inductor coil placed interior to the large superconducting magnet coil. Electricity is produced through magnetic induction when the expanding plasma causes magnetic field lines to cross through the inductor coil. The power processing equipment converts the electrical pulses produced by the inductor coil into $600 \mathrm{kV}, 0.4 \mu \mathrm{s}$ pulses for input to the driver.

There are two options for processing the power: The first is to compress each inductor pulse to $0.4 \mu \mathrm{s}$ without going through an intermediate DC stage. This is an advanced design that will rely on technology development past the 2020 time frame. The second option is rectification of the inductor pulses with capacitive storage. Option (2) is more massive because of the need for capacitors, but is a nearer term system. Option (2) is also more easily defined in terms of mass. The results of Option (2) are presented here.

Based on new technology, capacitor banks will have a specific mass of $400 \mathrm{~J} / \mathrm{kg}$ (Reference 12). Semiconductor banks, which serve as output switches to transfer energy from the capacitors to the load, have a specific mass of $5.5 \mathrm{~kJ} / \mathrm{kg}$. High and low voltage busses are required, with specific masses of $11 \mathrm{~kJ} / \mathrm{kg}$ each. Support structure for the power processing system equal to $10 \%$ of the equipment mass was also added. At $6 \%$ efficiency, $83.3 \mathrm{MJ}$ of energy input to the drivers are required. The power processing equipment mass is independent of rep rate, and thus will not vary with mission. The total weight of the power processing equipment is 260 metric tons. The mass breakdown is given in Table 8.

\section{TABLE 8}

POWER PROCESSING SYSTEM MASS

Item

Capacitor Bank

Semiconductor Bank

High Voltage Bus

Low Voltage Bus

Support Structure
Specific Mass $(\mathrm{kJ} / \mathrm{kg})$

0.4

5.5

11

11
Mass

(metric tons)

208

15

8

8

23 


\section{G. Power Processor Radiator}

The power processor radiator must dissipate the waste heat generated by each piece of the power processing equipment. The efficiency of each piece of equipment, and its estimated maximum operating temperature, are given in Table 9. The heat rejection requirement for each is given by

$$
Q=(\text { driver power })(1-\epsilon)
$$

where $\epsilon$ is the equipment efficiency. The radiator size depends on the rep rate because the driver power depends on rep rate.

The relatively low operating temperatures of the power conditioning equipment result in a large radiator area for heat dissipation. For a $30 \mathrm{~Hz}$ rep rate, $31,000 \mathrm{~m}^{2}$ of surface area is required. If placed on the cone beyond the driver radiator, a cone segment length of $36 \mathrm{~m}$ is required.

Because of the high vapor pressure of water and other candidate working fluids at the radiating temperature, a membrane heat pipe design is not feasible. Traditional armored radiator design is assumed, with a specific mass, based on current technology, of $7.7 \mathrm{~kg} / \mathrm{kW}$ at $100^{\circ} \mathrm{C}$ and $3.7 \mathrm{~kg} / \mathrm{kW}$ at $175{ }^{\circ} \mathrm{C}$. The total power processor radiator mass is 39 metric tons for the $5 \mathrm{~Hz}$ case and 236 metric tons for the $30 \mathrm{~Hz}$ case.

\section{TABLE 9}

POWER PROCESSING SYSTEM RADIATOR MASS

Equipment

1.Capacitor

Bank

2. Semiconductor

Bank

3. Low Voltage

Bus

4. High Voltage

Bus

Total
$.9989 \quad 450$

.9866
Radiating Dissipation Specific Radiator Temp for $5 \mathrm{~Hz}$ Mass Mass for

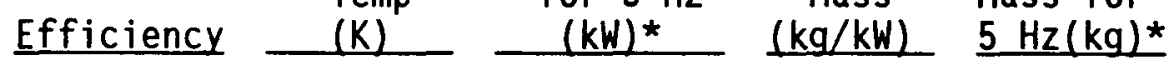

.9894

373

4400

$7.7 \quad 34,000$

$.9994 \quad 373$

250

7.7

1,900

.9989

450

460

$3.7 \quad 1,700$

460

3.7

1,700

39,300

*Multiply by 6 to obtain result for $30 \mathrm{~Hz}$ rep rate 
H. Payload

The payload is assumed to be 100 tons. This includes habitat modules, manned landing and ascent vehicles, and unmanned cargo landers.

\section{Structure}

A structural framework is required to support the thin-walled arrays of heat pipe radiators. A titanium framework, consisting of support trusses and lateral support rings, was designed for a maximum acceleration of $0.02 \mathrm{~g}$. A schematic is shown in Figure 6 for a $30 \mathrm{~Hz}$ rep rate. Titanium was chosen for its light weight and strength properties. The framework must be insulated from the hot radiator surface such that the temperature of the titanium does not exceed 600K. For a $30 \mathrm{~Hz}$ rep rate, the structural mass was found to be 190 metric tons, or $1.5 \mathrm{~kg} / \mathrm{m}^{2}$ of radiator surface. This mass is directly proportional to the rep rate, because the radiator area increases with rep rate.

\section{J. Fuel Tank Refrigerator}

The deuterium/tritium fuel and hydrogen expellant are stored cryogenically in fuel tanks until they are ready for injection into the thrust chamber. The tanks must either be refrigerated to remove heat generated by other parts of the spacecraft or insulated to keep the fuel frozen. The heat load on the tanks is difficult to determine, and the amount of insulation or refrigeration needed is not known. 50 metric tons has been selected as a rough order of magnitude estimate for a rep rate of $30 \mathrm{~Hz}$. The mass will vary directly with the amount of fuel taken on the mission.

\section{K. EM Pumps}

EM pumps are used to transport coolant through the feed pipes from the coil shield and driver modules to their associated heat pipe radiators. The pump mass is a function of the coolant volumetric flow rate, the electrical resistivity, and the pressure drop through the piping. An equation for the mass of an EM pump is given by Young et. al (Reference 13):

$$
\text { Pump Mass }=K\left[(\text { Pressure Drop) (Flow Rate) (Elect. Resistivity) }]^{0.656}\right.
$$

where $K$ is a proportionality constant. Two examples of pump designs from Reference 13 yielded a value of 0.07 for $K$ (assuming units of $\mathrm{kg}, \mathrm{N} / \mathrm{m}^{2}, \mathrm{~m}^{3} / \mathrm{s}$ and $\mathrm{ohm}-\mathrm{cm}$ for mass, pressure drop, flow rate and electrical resistivity, respectively).

The coolant flow rate increases with the heat rejection requirement, which is a function of rep rate. The pressure drop depends on both the length and the diameter of the feed pipes. As the rep rate increases, the feed pipe length increases, which has the effect of increasing the pressure drop. The diameter also increases, which has the effect of decreasing the pressure drop. As a result, the pressure drop is only a weak function of rep rate. The electrical resistivity is constant for a given coolant at a given temperature. 


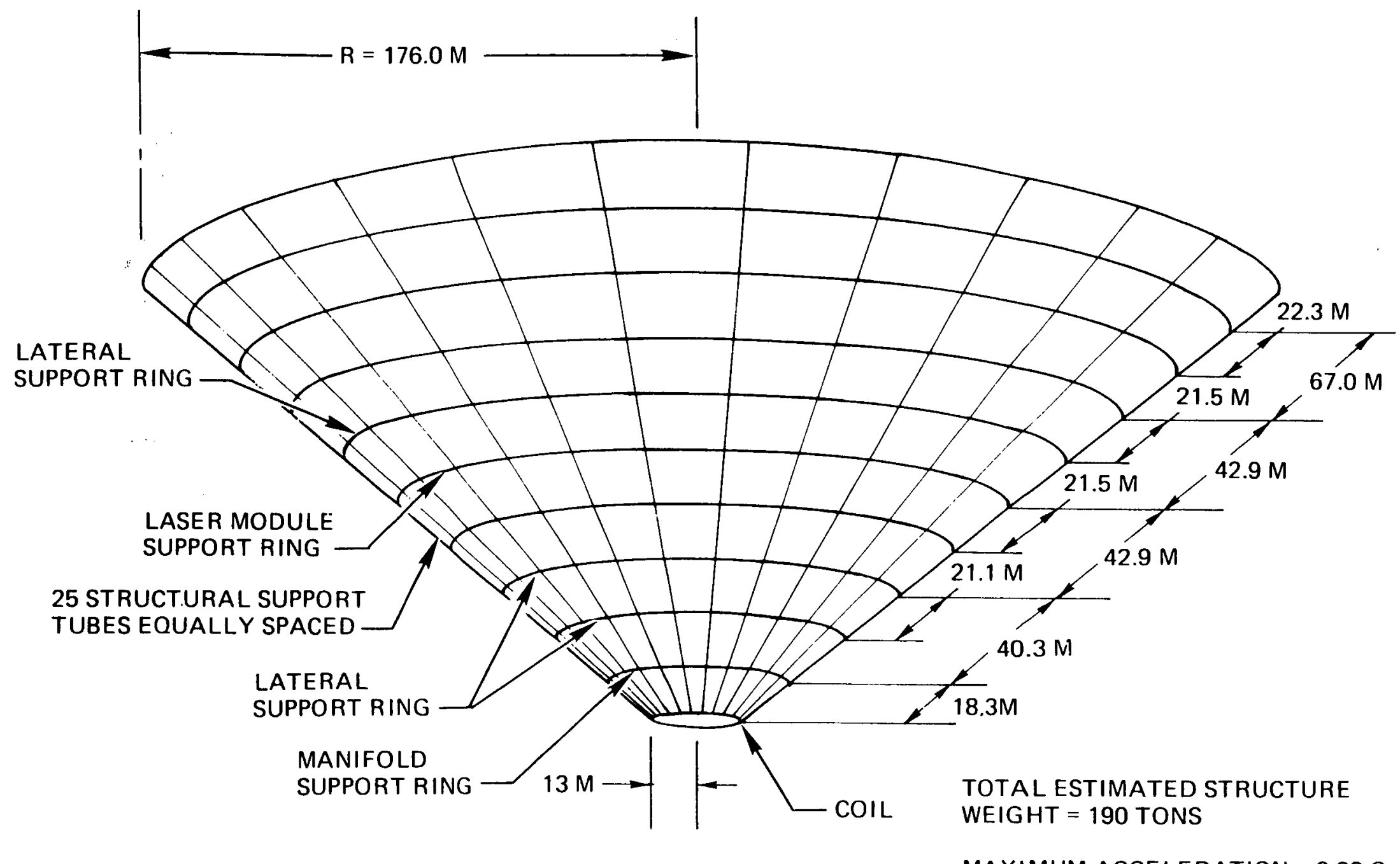

MAXIMUM ACCELERATION $=0.02 \mathrm{G}$

FIGURE 6. CONCEPTUAL STRUCTURAL FRAMEWORK 
The current Gevaltig Mars Mission design includes 64 coil shield EM pumps, 900 driver EM pumps and 1374 laser mirror EM pumps. The resulting total pump masses are 330 metric tons for a rep rate of $30 \mathrm{~Hz}$, and 62 metric tons for a rep rate of $5 \mathrm{~Hz}$.

The results show that EM pumps are a significant part of the total IFR mass. It is possible to reduce the EM pump mass, at the expense of increasing the radiator mass, by lengthening the individual heat pipes so that the total number of feed pipes can be reduced. Reducing the number of feed pipes reduces the number of pumps required, and also reduces the pressure drop through each pipe, which allows smaller pumps to be used. However, lengthening of the heat pipes requires either additional hardening of the surface, or additional spare heat pipes to counteract the increased chance of micrometeoroid penetration of the larger pipes. Thus, the mass of the heat pipe radiators will increase if the number of feed pipes are decreased.

Optimization of the design is done by varying the heat pipe array survivability and wall thickness until the total mass (heat pipes plus EM pumps) is minimized. Optimization reduces the total pump mass from 330 tons to 240 tons for the 30 $\mathrm{Hz}$ case and from 62 to 46 tons for the $5 \mathrm{~Hz}$ case. The associated increases in radiator mass are 57 tons and 10 tons for the $30 \mathrm{~Hz}$ and $5 \mathrm{~Hz}$ cases, respectively, resulting in a net mass savings of 30 tons and 5 tons for the two cases. These optimized masses are reflected in Table 2.

\section{Crew Shield}

In order to protect the crew from cosmic rays, solar cosmic rays, and major proton events from the sun, an estimated $1.5 \mathrm{~m}$ of liquid must surround the crew quarters. The Gevaltig crew shield is made up of liquid hydrogen, which surrounds two habitat modules measuring $5 \mathrm{~m}$ in diameter and $15 \mathrm{~m}$ in 1 ength. The hydrogen is contained within a $1 \mathrm{~cm}$ thick steel tank. The total mass of the crew shield is approximately 140 metric tons.

\section{Startup Reactor}

An SP-100 type reactor will be included on board to provide the startup power to thaw the coil shield, driver and mirror coolants, and to supply the $83 \mathrm{MJ}$ necessary to fire the first driver pulse. This reactor is estimated to weigh 5 metric tons for the $5 \mathrm{~Hz}$ rep rate and 20 metric tons for the $30 \mathrm{~Hz}$ rep rate. A more in-depth description of the startup reactor is provided in Section $V$.

N. Pellet Factory

The pellet factory will be used to manufacture the DT fuel pellets with surrounding hydrogen expellant. Depending on the mission, the fuel pellets may be manufactured prior to take-off, and then stored in the ready state, or manufactured on board. For the Mars mission and the Titan mission, it is assumed that the pellets are pre-made. No mass is included for the pellet factory in this estimate. 
0. Laser Mirrors and Pellet Launchers

Approximately 100 final laser mirrors focus the driver energy on the fuel pellet. The mirrors have a surface area of $40 \mathrm{~m}^{2}$, and are made of beryllium with another material as a backing (Reference 4). A backing material of a density similar to steel and $1 \mathrm{~cm}$ thick results in a mass of 6.4 tons for the laser mirrors. Inclusion of structural support will bring the mass of the mirrors to approximately 8 tons.

The pellet launchers are positioners from which the fuel pellets are fired into the thrust chamber. There may be several launchers for this purpose; however, the total mass is expected to be negligible when compared to the mass of the spacecraft.

\section{P. Coolant System for Laser Mirrors and Pellet Launchers}

Neutrons and $x$-rays streaming out in all directions from the fusion reaction will come into contact with the final laser mirrors and pellet launchers, which are not protected by the coil shield. It is estimated that these structures absorb about $1 \%$ of the energy in the neutrons and $x$-rays. For a rep rate of 30 $\mathrm{Hz}, 1690 \mathrm{MW}$ are absorbed.

The material of construction of the laser mirrors and pellet launchers limit their operating temperature to $900 \mathrm{~K}$. These components must be cooled to remove excess heat. A sodium heat pipe radiator similar to the one used for the drivers is proposed. This radiator has a specific mass of $.083 \mathrm{~kg} / \mathrm{kW}$ at $30 \mathrm{~Hz}$ and $.060 \mathrm{~kg} / \mathrm{kW}$ at $5 \mathrm{~Hz}$. The resulting mass of the cooling system is thus 139 tons for the $30 \mathrm{~Hz}$ rep rate and 17 tons for the $5 \mathrm{~Hz}$ case. 


\section{COMPONENT MASS RESULTS FOR THE TITAN MISSION}

The component masses listed in Table 2 are for a mission to Mars. The mission duration is 100 days, and includes 8 days of thrusting each way with a final coast velocity of $50 \mathrm{~km} / \mathrm{s}$. Component masses for the Titan mission will vary from the Mars mission for three reasons: 1) The mission duration is longer, 2) the rep rate of the engine may be different, and 3) the number of days of thrust may change. The mission duration will have an effect on the design of the radiators, which must have an increased survivability from micrometeoroids. The rep rate will have an effect on the size of the radiators. The number of days of thrust will affect the mass of the fuel tanks, which is directly proportional to the amount of fuel needed.

A computer spreadsheet was set up which calculates component masses for any given rep rate and mission duration, so that the component mass for the Titan mission can be determined.

A comparison of component masses (those that vary with mission) for the Mars and Titan missions is given in Table 10. A maximum rep rate of $30 \mathrm{~Hz}$ was assumed for each mission. In order to calculate the Titan mission component masses, the same fuel consumption as the Mars mission and a round trip mission duration of 600 days were assumed.

In Table 10, the fuel tank mass is the same for both missions, because fuel consumption is assumed to be the same. The coil shield radiator, driver radiator, and laser mirror radiator increase slightly in mass, because the heat pipes must be further fractionated for long duration micrometeroid protection. This fractionation requires additional feed pipes to supply coolant to all the heat pipes. Additional EM pumps are also required, and the fractionation of feed pipes results in a larger pressure drop through each of the pipes, increasing the size of each pump. As a result, the mass of the EM pumps increases from 240 tons to 360 tons. The power processor radiator mass does not change in this analysis, because it is assumed to be a traditional armored design. The total increase in mass for the Titan mission is approximately 260 metric tons, assuming a maximum rep rate of $30 \mathrm{~Hz}$. For the $5 \mathrm{~Hz}$ case, the Titan mission has a mass increase of approximately 40 tons. 


\section{TABLE 10}

COMPARISON OF MARS MISSION AND TITAN MISSION MASSES FOR A REP RATE OF $30 \mathrm{HZ}$

Mars Mission

(metric tons)

Fue] Tank

Coil Shield Radiator

Driver Radiator

Power Processor Radiator

EM Pumps

Laser Mirror Radiator
410

210

290

240

240

140
Titan Mission

(metric tons)

230

370

240

360

180

Total Mass Increase $=260$ tons 


\section{ENGINE STARTUP REQUIREMENTS}

A small nuclear power system will be carried on board to thaw the liquid metal radiator coolants and to provide the startup power to fire the first laser pulse.

The mission to Titan requires 150 metric tons of $L i$ coolant for the coil shield radiator, and 200 metric tons of $\mathrm{Na}$ coolant for the driver and laser mirror radiators. Assuming a 5-day thaw period, 1 MWe of power is necessary to heat the coolants from $0 \mathrm{~K}$ to above the melting temperature. Electrical trace heating will be installed along the feed pipes to heat the coolant via electrical resistance. Heat pipes will be thawed by heat transfer from the feed pipes into the embedded evaporator sections.

Additional power is necessary to provide make-up energy for heat lost by radiation from the surface of the feed pipes during the thaw. The maximum makeup power required is equal to that lost toward the end of the thaw period, when the coolants reach their melting temperature. The feed pipes are assumed to have an emissivity of 0.5 . The presence of the bumpers on the feed pipes reduces radiative heat transfer by a factor of two. Heat loss to the heat pipes can be eliminated during the thaw by maintaining them in a rolled position. This will be possible due to their thinness and will also reduce micrometeoroid damage. Calculations show that the total heat loss by radiation based on these assumptions is approximately 5 MWe. Including the power necessary to thaw the coolants, a 6 MWe reactor is required.

The large power required to generate the first laser pulse can be generated over a period of time, and stored in a flywheel or other type of electrical storage device. The reactor power needed is equal to

$$
P_{c}=E_{B} / t \dot{\epsilon}
$$

where $P_{C}$ is the reactor power to provide the first pulse, $E_{B}$ is the burst energy required $(\mathrm{J}), t$ is the energy accumulation period $(s)$ and $\epsilon$ is the power processing equipment efficiency. For a burst energy of $83.3 \mathrm{MJ}$, an energy accumulation period of 12 hours, and a power conditioning efficiency of 0.99 , a reactor power of $2.0 \mathrm{kWe}$ is required. A schematic of startup requirements is shown in Figure 7.

The 6 MWe startup reactor will provide power for both the initial thaw and the laser power storage system. A total of $84.4 \mathrm{MJ}$ must be accumulated in storage before the laser firing can be achieved. The burst of power to the laser is released in a $0.4 \mu \mathrm{s}$ time span, at a power level of $2 \times 10^{8}$ MWe. The $6 \%$ efficient laser drivers reject $78.3 \mathrm{MJ}$ of waste heat, and the power conditioning system rejects $1.1 \mathrm{MJ}$ of waste heat between each laser pulse. 


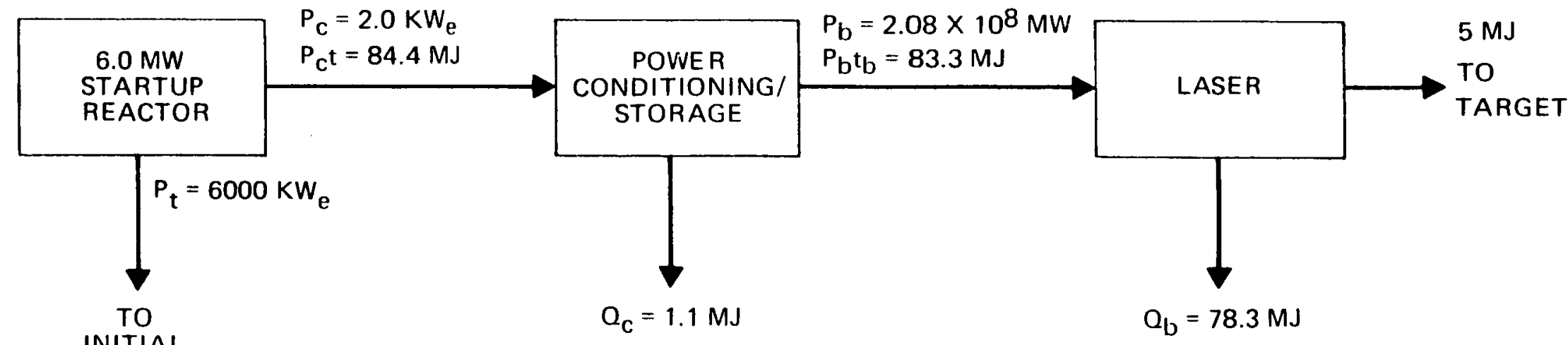

INITIAL

THAW 
After the first driver pulse is fired, the expanding plasma of the fusion reaction generates electricity via the inductor coil for the second and subsequent pulses.

The mass of the startup reactor was calculated using the RSMASS code (Reference 14). This code calculates reactor and shield masses for three types of reactors: gas cooled, liquid metal cooled, or thermionic. A liquid metal cooled reactor, with a potassium Rankine power conversion cycle, was chosen for the Gevaltig.

The round trip mission duration to Titan is estimated to be two years. The reactor lifetime, however, does not have to be equal to the mission duration, because it is only used for startup, and can be shut down for the duration of the flight. A reactor lifetime of one year was assumed for the mission.

The fuel for the reactor is uranium-235 with $70 \%$ fuel enrichment. The mass of the reactor fuel is calculated based on a maximum permitted burnup fraction of 0.065. The reactor is a fast reactor, i.e., no moderator is present. The structural mass of the core was calculated using a ratio of structural volume to fuel volume of 0.65 , and an average structural density of $12,000 \mathrm{~kg} / \mathrm{m}^{3}$. The reflector is approximated as a spherical shell of $3000 \mathrm{~kg} / \mathrm{m}^{3}$ density and a thickness equal to half the radius of the core.

A pressure vessel surrounds the reactor outside the reflectors. The vessel is made of stainless steel with a density of $8000 \mathrm{~kg} / \mathrm{m}^{3}$ and an ultimate tensile strength of $280 \mathrm{MPa}$. A safety factor of four was included to take into account specific vessel stresses and thermal steady state and transient conditions.

The reactor shield includes both a neutron and a gamma shield and is assumed to be a shadow shield with a half angle of $15^{\circ}$. The shield thicknesses are based on a payload separation distance of $25 \mathrm{~m}$, a maximum allowed payload neutron dose of $7 \times 10^{10} \mathrm{nvt}\left(\mathrm{n} / \mathrm{cm}^{2}\right)$, and a maximum allowed payload gamma dose of $25 \mathrm{rad}$. These are allowable doses to a manned payload based on a suggested guideline of $50 \mathrm{REM} /$ year for space station inhabitants. Attenuation of gamma rays by the neutron shield is taken into account. A total gamma shield thickness of $21 \mathrm{~cm}$ and a total neutron shield thickness of $76 \mathrm{~cm}$ resulted. The neutron shield is made of lithium hydride and the gamma ray shield is made of aluminum. The reactor and shield mass breakdown is given in Table 11.

A potassium Rankine power conversion system was chosen to provide electrical power to the trace heating elements and the flywheel. The computer code ALKASYS (Reference 15) was used to estimate the mass of the system. Results are given in Table 12 . 


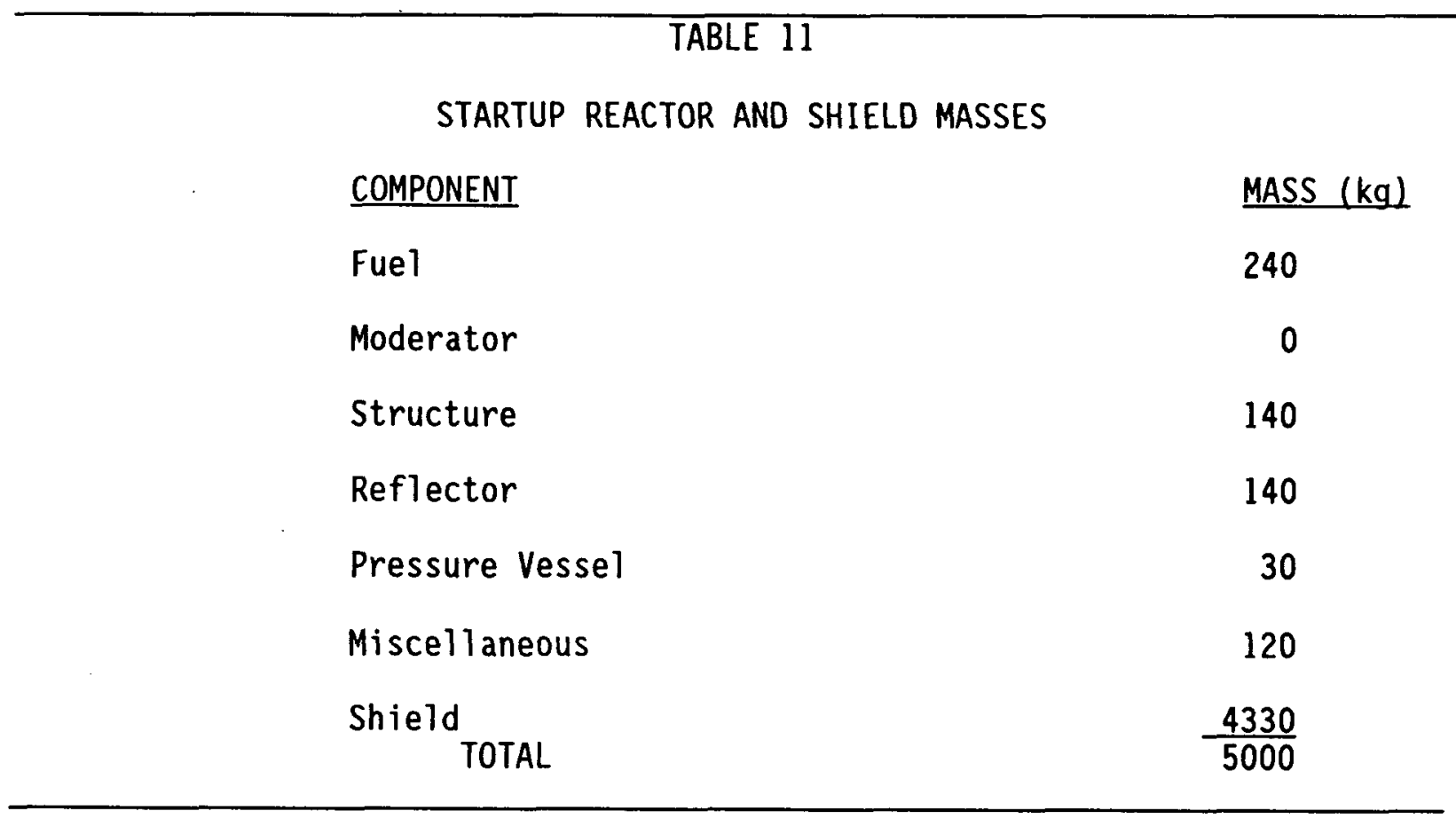

TABLE 12

STARTUP REACTOR POWER CONVERSION SYSTEM MASSES

COMPONENT

Boiler

Turbine

Generator

Feed Heaters

Piping

Lithium Pump

Potassium Feed Pump

Radiator

Power Conditioning TOTAL
$\operatorname{MASS}(\mathrm{kg})$

400

2100

2200

40

90

1100

280

3200

1500

10,900 
The cycle has a turbine inlet temperature of $1389 \mathrm{~K}(2500 \mathrm{R})$, a condenser temperature of $950 \mathrm{~K}(1710 \mathrm{R})$ and a cycle efficiency of $23.5 \%$. Lithium coolant is pumped by an EM pump from the reactor to the shell side of a potassium boiler. Saturated potassium vapor exits the tube side of the boiler and is delivered to a seven stage turbine, with a relatively small stream diverted to drive the feed pump. Upon exiting the turbine, vapor is condensed around the evaporator sections of a radiator heat pipe array. Condensate is then pumped through three feed heaters to the boiler entrance.

The radiator model in the ALKASYS program is a heat pipe array configured to fit within the launch bay of a space shuttle. Since this is not a constraint for the Gevaltig rocket, the heat pipe radiators have been designed in a manner similar to the driver heat rejection system.

The heat pipes are assumed to operate at a temperature $50^{\circ} \mathrm{C}$ less than the potassium condensing temperature. For $6000 \mathrm{kWe}$ net electric power, approximately $21,000 \mathrm{~kW}_{\mathrm{t}}$ must be rejected from the condenser. At a specific mass of $0.15 \mathrm{~kg} / \mathrm{kW}_{\mathrm{t}}$ (based on the driver radiator), a radiator mass of $3200 \mathrm{~kg}$ is obtained.

The total mass of the startup reactor system, including the power conversion system and power conditioning, is approximately 16 metric tons. 


\section{MISSION ANALYSIS METHODOLOGY AND RESULTS}

NASA Lewis performed mission analysis calculations for a manned round trip to Titan, the sixth satellite of Saturn, using the Gevaltig fusion rocket. The analysis was performed by calculating launch mass for various values of mission duration, pellet mass, and rep rate. Component masses from the previous sections of this report were utilized in calculating mission performance. Because these masses vary with each iteration, a curvefit was derived so that power system mass can be calculated directly from jet power.

The following equations were used as a basis for performing the mission analysis:

Jet Power (MW) is given by

$$
P_{j}=E G F \eta^{2} R
$$

where $E$ is driver energy on target (MJ), $G$ is the target gain, $F$ is the energy fraction to the debris, $\eta$ is the conversion efficiency of debris energy to momentum, and $\mathrm{R}$ is the rep rate. For the Gevaltig rocket, a driver energy of $5 \mathrm{MJ}$ on target, a gain of 1500 , 25\% energy fraction to the debris, and $60 \%$ conversion efficiency are reasonable values. Equation (7) then becomes

$$
P_{j}=675 R
$$

Specific impulse (s) and thrust (N) are given by

$$
I_{s p}=\left(\eta / g_{c}\right)(2 E G F / M)^{1 / 2}
$$

and

$$
\text { thrust }=\eta \mathrm{R}(2 \mathrm{EGFM})^{1 / 2}
$$

When the values for the Gevaltig rocket are inserted into these equations, they become

$$
I_{s p}=3749 / M^{1 / 2}
$$

and

$$
\text { thrust }=36,740 \mathrm{RM}^{1 / 2}
$$

where $M$ is the pellet mass in $\mathrm{kg}$. 
In Figure 8, the power system mass of the spacecraft, including all components listed in Table 2 except the payload and crew shield, is plotted against jet power. The power system mass $\left(M_{P S}\right)$ is made up of two parts - mass that does not vary with jet power $\left(M_{0}\right)$, depicted by the intercept in Figure 8 , and mass that increases as the jet power increases. Components that do not vary with jet power include the driver, coil, coil shield, startup reactor, laser mirrors and power processing system (excluding power processor radiator). The total mass of these components is approximately 700 tons. Component masses that vary with jet power include all the radiators, fuel tanks, structure, and EM pumps.

The curve in Figure 8 is very nearly a straight line, but can be fitted more accurately to a parabolic function, in which the power system mass (metric tons) is given by

$$
M_{P S}=\alpha P_{j}^{2}+\beta P_{j}+M_{0}
$$

where $\alpha$ is $6.7 \times 10^{-7}, \beta$ is 0.087 and $M_{0}$ is 700 .

The curve in Figure 8 was plotted for the Titan mission based on the previously described component masses and the following assumptions: mission duration of 600 days (round trip) increasing linearly to a duration of 900 days as the rep rate decreases to $5 \mathrm{~Hz}$, and a fuel consumption of approximately 4100 metric tons for $30 \mathrm{~Hz}$, decreasing linearly to 700 metric tons for $5 \mathrm{~Hz}$. These assumptions are necessary to calculate fuel tank mass and the required radiator fractionation, but are not expected to have a large effect on the resulting curvefit.

The launch mass is determined by the following equation:

$$
M_{L}=M_{P}+M_{F}+M_{P S}
$$

where $M_{p}$ is the mass of the payload and crew shield, and $M_{F}$ is the mass of the propellant. $M_{F}$ is determined by the mission analysis calculations. A tankage factor of $7 \%$ of the return propellants was also added.

Mission analysis calculations were performed for engine rep rates of 5 and 30 $\mathrm{Hz}$ and for pellet masses ranging from 10 to 80 grams. Values of jet power, I thrust, and power system mass for these cases are given in Tables 13 and 14. Some of these cases resulted in improper convergence and thus are not reported.

A multiple impulse trajectory program, MULIMP2, was used for the mission analysis. Mission parameters are as follows:

Departure year - 2020

Mission duration at Titan - 30 days

Departure altitude - Lunar orbit

Total trip time (sum of the duration of the outbound leg, stay time and return leg) - 250 to 500 days. 


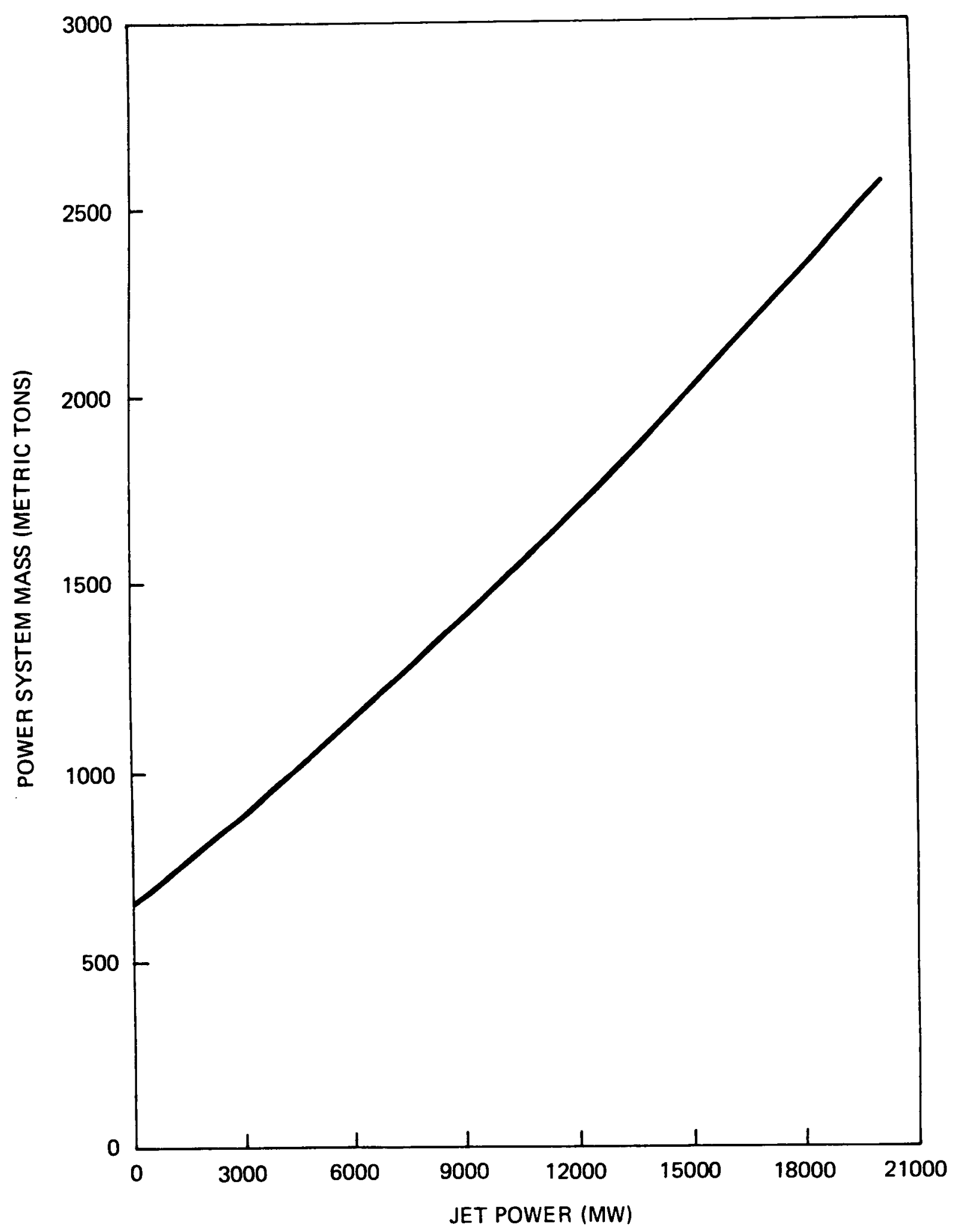

FIGURE 8. POWER SYSTEM MASS VS JET POWER FOR TITAN MISSION 
TABLE 13

DATA USED FOR THE 5 HZ TITAN MISSIONS

PELLET
MASS

(g)

10

20

30

40

50

60

70

80
JET

POWER

(MW)

3375

3375

3375

3375

3375

3375

3375

3375
$\mathrm{I}_{\text {SP }}$

(sec.)

37467

26493

21631

18733

16756

15296

14161

13247
THRUST

(N)

18371

25981

31820

36742

41079

45000

48606

51962
POWER

SYSTEM MASS

(kg)

960,468

960,468

960,468

960,468

960,468

960,468

960,468

960,468

\section{TABLE 14}

DATA USED FOR THE $30 \mathrm{HZ}$ TITAN MISSIONS

\section{PELLET \\ MASS}

(g)

10

20

30

40

50

60

70

80
JET

POWER

(MW)

20250

20250

20250

20250

20250

20250

20250

20250
$\mathrm{I}_{\mathrm{SP}}$

(sec.)

37467

26493

21631

18733

16756

15296

14161

13247
THRUST

(N)

110227

155885

190919

220454

246475

270000

291633

311769
POWER

SYSTEM MASS

$(\mathrm{kg})$

$2,630,608$

$2,630,608$

$2,630,608$

$2,630,608$

$2,630,608$

$2,630,608$

$2,630,608$

$2,636,608$ 
The payload was assumed to be 120 metric tons delivered to Titan consisting of a 20 metric ton mass jettisoned at Saturn and a 100 metric ton crew module, which returns to earth.

Gravitational losses were taken into account by adding a percentage to the propellant mass using results from one way trip times calculated by the Varitop program. These losses varied from $3 \%$ up to $40 \%$ in some cases and corrected for the "ideal" rocket assumptions made in the MULIMP2 Program. Significantly long burn times compared to the trip times were encountered in many cases, making this correction necessary.

Results of the analysis are shown in Figures 9 through 12. In Figure 9, the total propellant consumed is plotted versus trip time for an engine rep rate of $5 \mathrm{~Hz}$. Pellet masses varying from 10 grams to 60 grams are shown. The minimum propellant masses were obtained for a pellet mass of 10 grams. Although the thrust obtained with a 10 gram pellet is less than with larger pellets, the increase in $I_{s p}$ results in less propellants consumed. The total launch mass is plotted versus trip time in Figure 10. The minimum launch masses are also associated with a 10 gram pellet size. A launch mass as $10 w$ as 2500 metric tons can be obtained.

Total propellant consumed and initial launch mass are plotted vs. trip time for a rep rate of $30 \mathrm{~Hz}$ in Figures 11 and 12 . At $30 \mathrm{~Hz}$, the available thrust is much higher, but the power system mass increases significantly. It can be seen by comparison that the launch masses for a $30 \mathrm{~Hz}$ rep rate are higher than a 5 $\mathrm{Hz}$ rep rate, for the same values of trip time.

Based on the results shown here, an optimum mission scenario (trip time, launch mass and propellant mass) can be selected by trading off the advantage of a shorter trip time with the advantage of a lower launch mass. This tradeoff depends upon mission objectives. Usually, for a manned mission, as short a trip time as possible is desired to prevent hazards to the astronauts, which include radiation from space and calcium and blood volume losses due to the zero gravity environment. These considerations may outweigh the extra cost associated with a heavier launch mass.

Because the lowest launch masses were obtained for a pellet mass of 10 grams and a rep rate of $5 \mathrm{~Hz}$, it is possible that a more optimum solution may be found at lower rep rates and pellet sizes. Additional cases were run for a rep rate of $1 \mathrm{~Hz}$ and a pellet mass of $1 \mathrm{gram}$. However, under these conditions the rate of mass expellant is so small that extremely long burn times resulted, exceeding the trip time calculated by the MULIMP2 software. These cases, of course, are not realistic. An update in the software to resolve this problem is necessary for performing additional mission calculations at these conditions. A mission scenario even more optimal than those shown here may possibly be found. 
Approximately $44 \mathrm{mg}$ of DT is contained within each fuel pellet, $26.5 \mathrm{mg}$ of which is tritium. The amount of tritium to be carried on board at launch is plotted vs. trip time for various pellet sizes and rep rates in Figure 13 . The $5 \mathrm{~Hz}$ rep rate cases utilize the least amount of tritium; from 2 to 5 metric tons. This amount of tritium can be produced by the year 2020 if heavy water reactors such as the CANDU are adopted on an international scale. The minimization of tritium fuel should be taken into consideration when determining optimum mission scenarios. 
FIGURE 9

PROPELLANT CONSUMPTION FOR ROUND TRIP MISSION TO TITAN- 5 HZ REP RATE

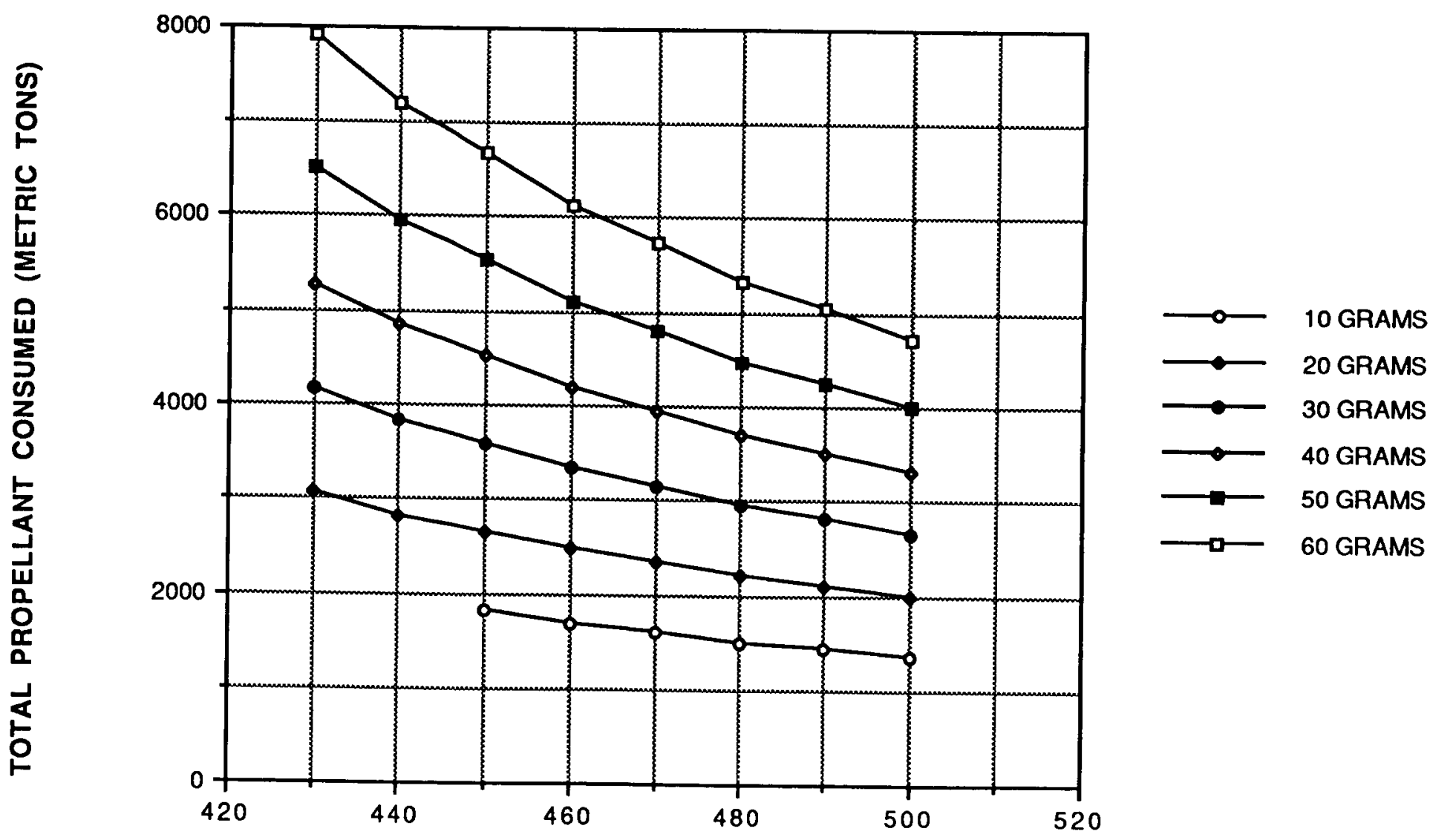

TOTAL TRIP TIME, DAYS 
FIGURE 10

LAUNCH MASS FOR ROUND TRIP TO TITAN- 5 HZ REP RATE

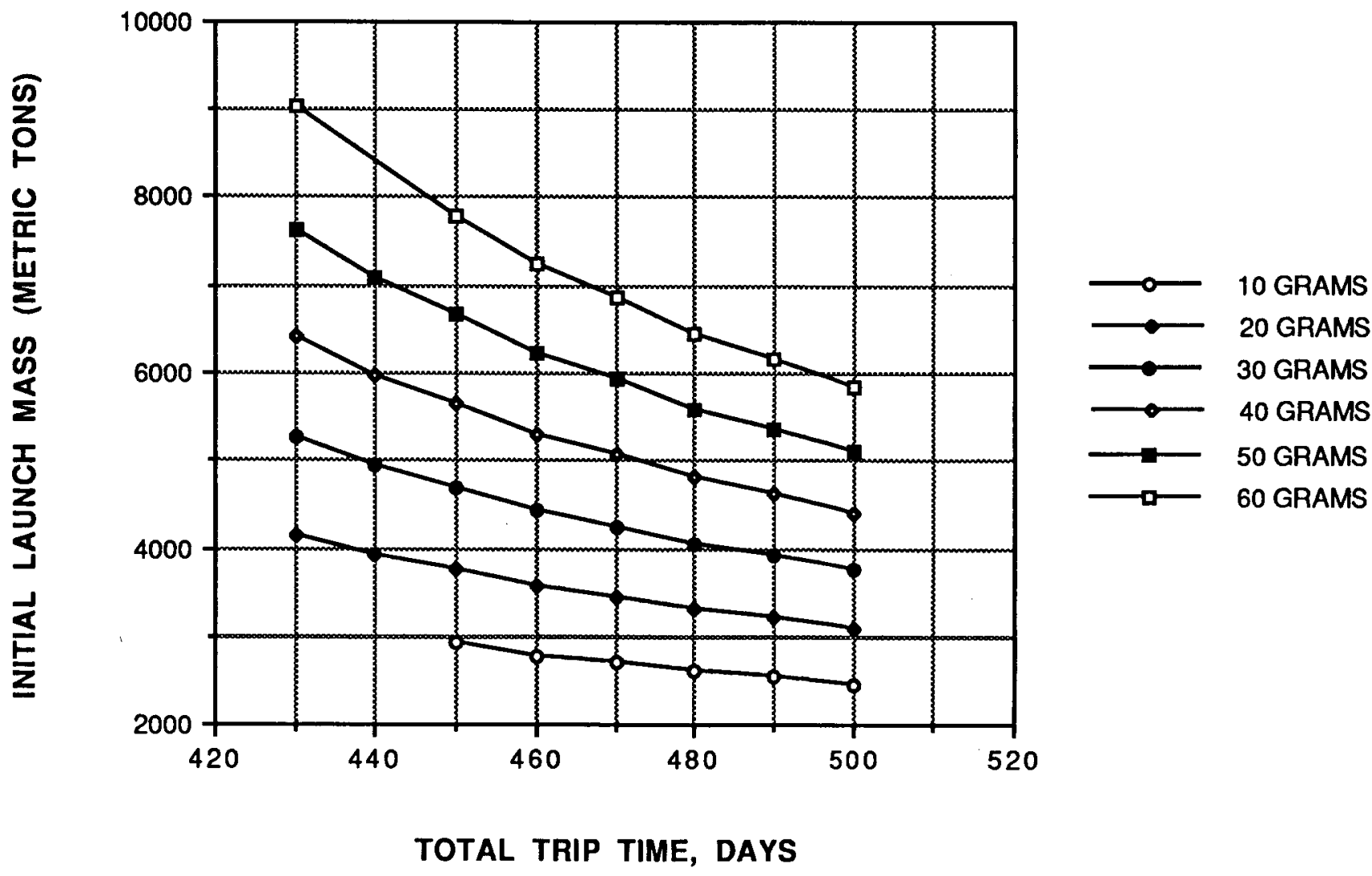


FIGURE 11

PROPELLANT CONSUMPTION FOR R.T. MISSION TO TITAN- 30 HZ REP RATE

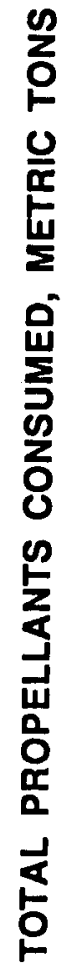

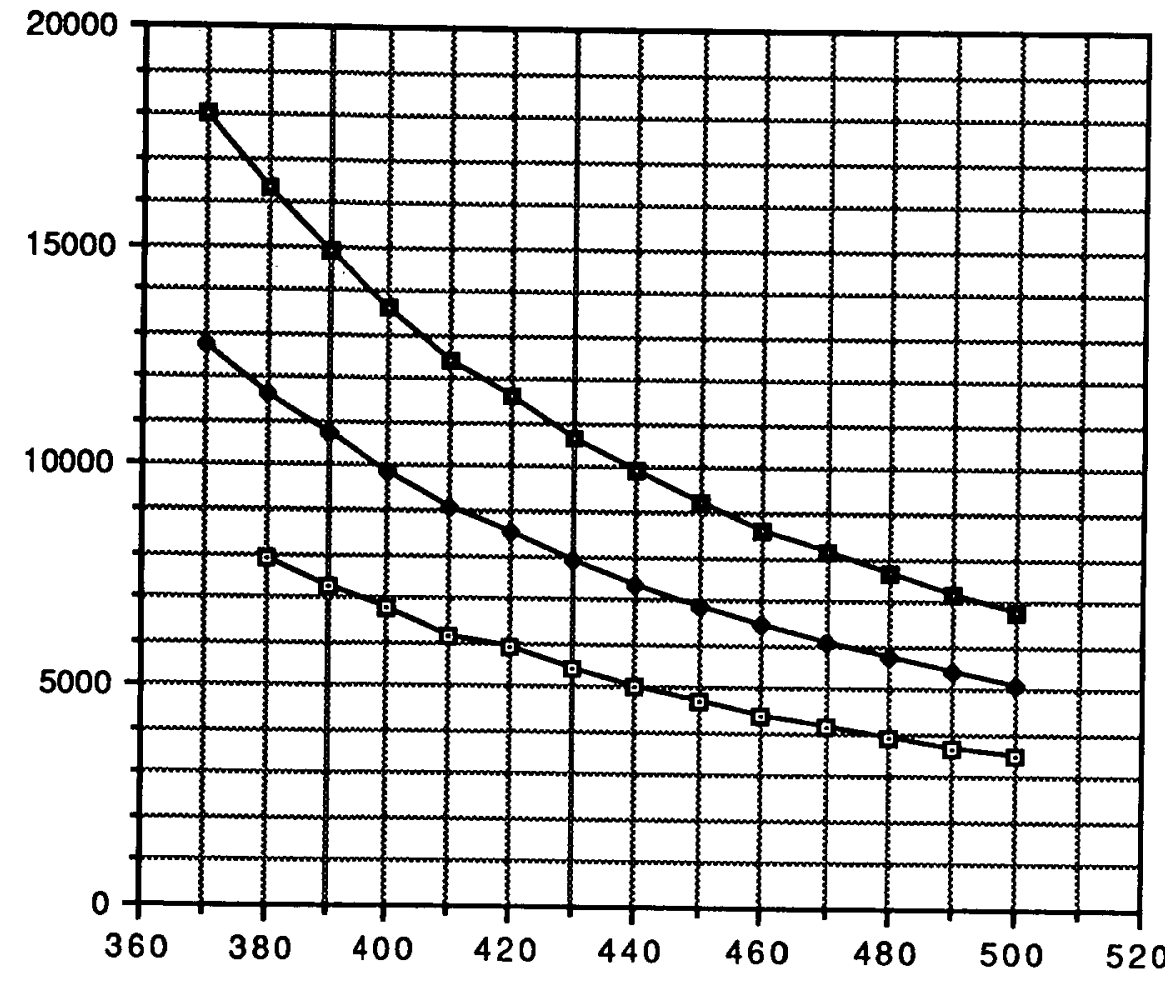

- 10 GRAMS

20 GRAMS

$\longrightarrow 30$ GRAMS

TOTAL TRIP TIME, DAYS 
FIGURE 12

LAUNCH MASS FOR ROUND TRIP TO TITAN- 30 HZ REP RATE

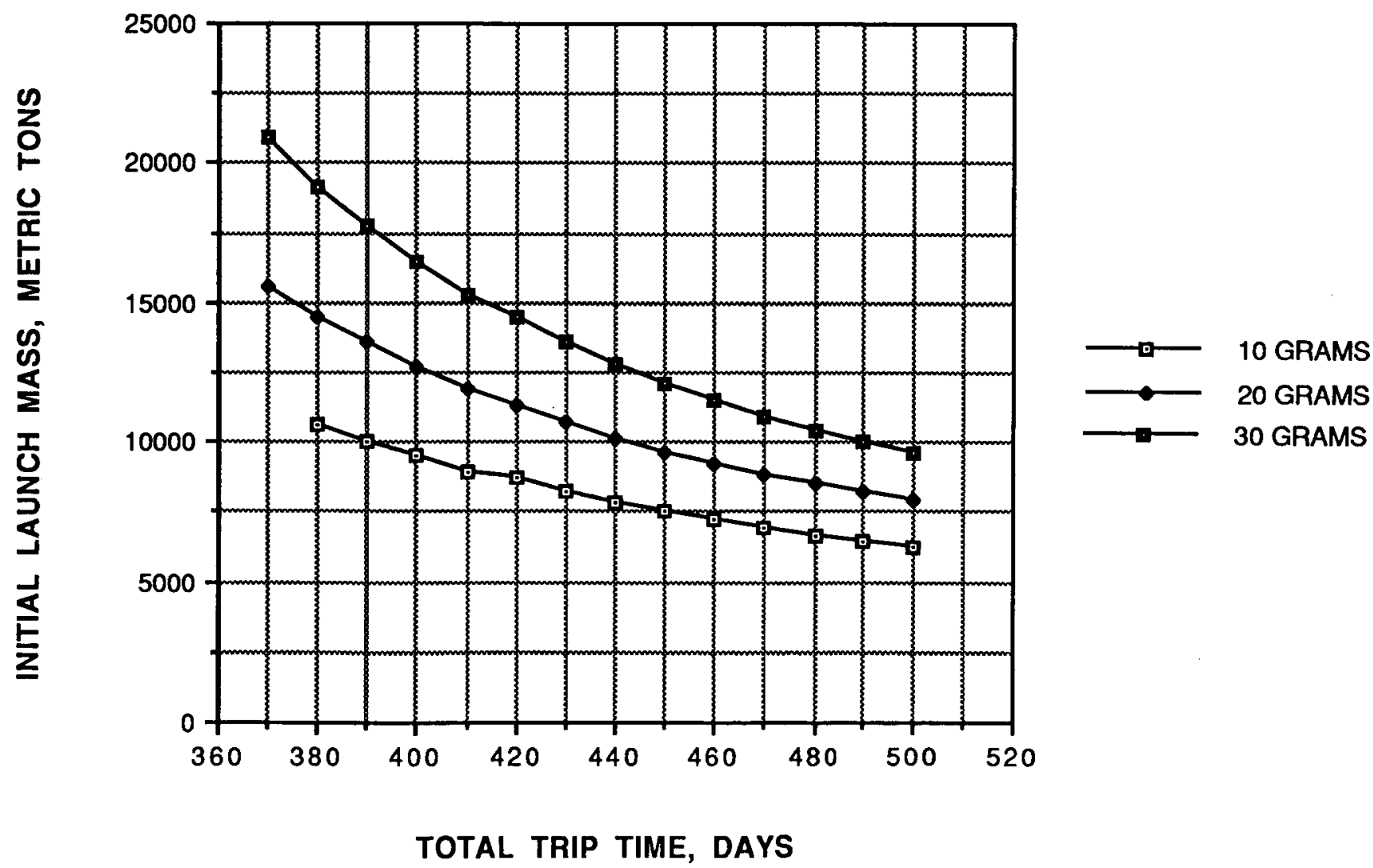




\section{FIGURE 13}

\section{TRITIUM FUEL REQUIREMENTS AT LAUNCH FOR TITAN MISSION}

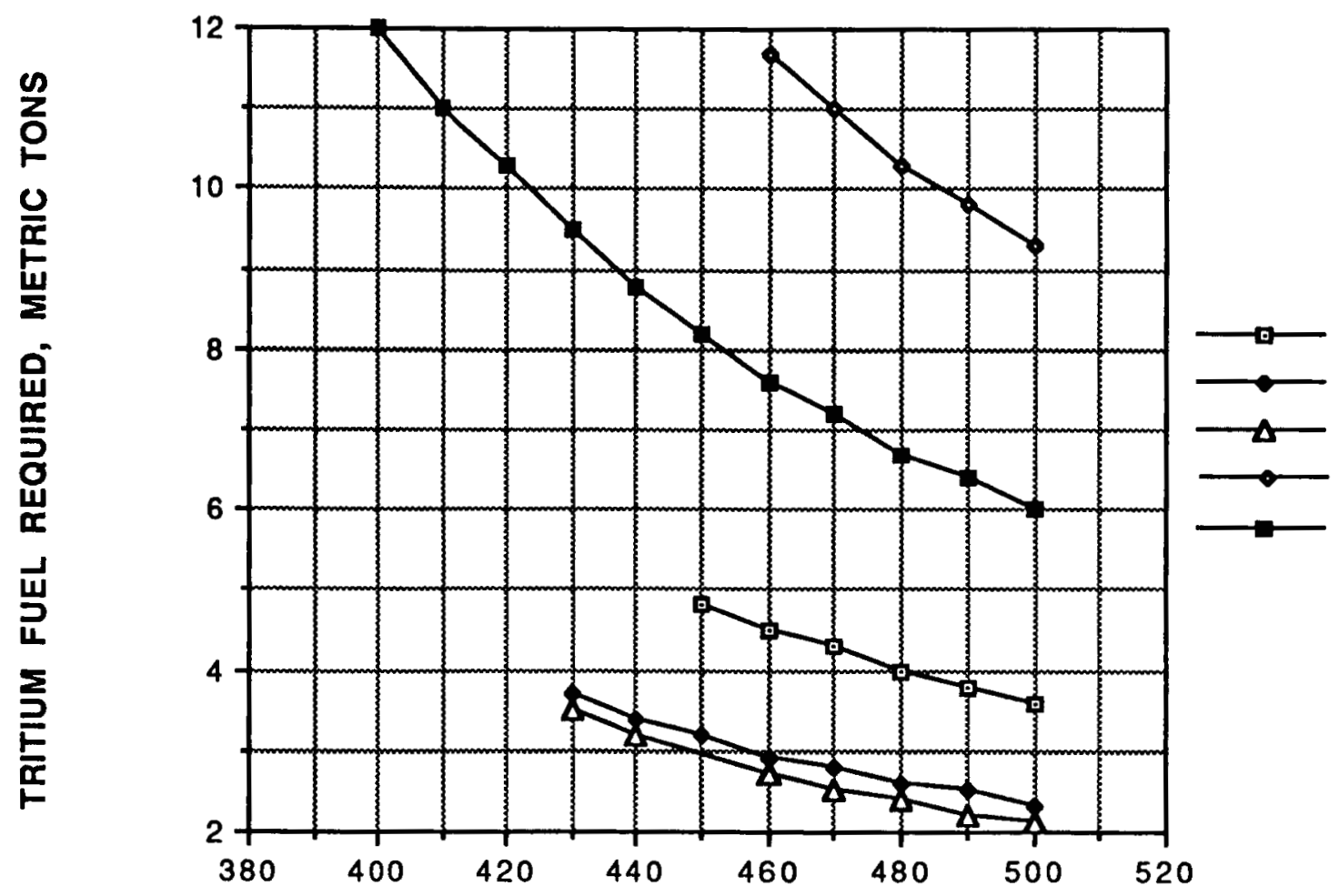

10 GRAMS, $5 \mathrm{HZ}$

30 GRAMS, $5 \mathrm{HZ}$

60 GRAMS, $5 \mathrm{HZ}$

10 GRAMS, $30 \mathrm{HZ}$

30 GRAMS, $30 \mathrm{HZ}$

TOTAL TRIP TIME, DAYS 


\section{CONCLUSIONS}

Component masses for the Gevaltig, an inertial confinement fusion rocket, were presented in this report for missions to both Mars and Titan. These component masses vary with jet power, and must be calculated in order to do mission analysis computations. Component masses as a function of jet power were presented as a polynomial equation in order to facilitate the mission analysis.

Mission analysis results show that a manned mission to Titan can be accomplished with a round trip time as low as 1 year. However, optimization of the mission performance must take into account initial launch mass and a minimization of tritium fuel requirements, which may increase the trip time to 1.5 years. The optimum mission scenario from both a duration and fuel standpoint is probably at a rep rate of less than $5 \mathrm{~Hz}$ and a pellet mass of less than 10 grams. An update in the computer software used to perform this analysis is necessary in order to completely optimize mission performance. 


\section{REFERENCES}

1. C. Orth et al, "Transport Vehicle for Manned Mars Missions Powered by Inertial Confinement Fusion," Lawrence Livermore National Laboratory, Livermore, Cal ifornia, AIAA-87-1904 (1987)

2. H. Price, Jet Propulsion Laboratory, Private Communication, May 1986.

3. W. Meier et al, "Inertial Fusion Power for Space Applications", Lawrence Livermore National Laboratory, Livermore, California, IECEC-869419 (1986)

4. C. Orth, Lawrence Livermore National Laboratory, Private Communication, January 1988.

5. J. H. Pitts and C.E. Walter, "Conceptual Design of a 10 MW Nuclear Rankine System for Space Power" Lawrence Livermore National Laboratory, Livermore, CA, J.Spacecraft, Vol. 7, No. 3, March 1970

6. A. J. Buschman, Jr., and C. M. Pittman, "Configuration Factors for Exchange of Radiant Energy Between Axisymmetrical Sections of Cylinders, Cones and Hemispheres and Their Bases," NASA-TND-944, 1961.

7. M. A. Merrigan et al, "Heat Pipe Technology Development for High Temperature Space Radiator Applications, "Los Alamos National Laboratory, Los Alamos, New Mexico, IECEC 849453 (1984)

8. D.R. Sawle, "Hypervelocity Impact in Thin Sheets and Semi-Infinite Targets at $15 \mathrm{~km} / \mathrm{sec}^{\prime}$, AIAA Journal, Vol. 8, No. 7, 1970.

9. A. P. Fraas, "Protection of Spacecraft from Meteoroids and Orbital Debris," Oak Ridge National Laboratory, Oak Ridge, Tenn., ORNL/TM-9904 (1986)

10. "Meteoroid Environment Model - 1970 (Interplanetary and Planetary)," National Aeronautics and Space Administration, NASA-SP-8038 (1970)

11. R. A. Hyde, "A Laser Fusion Rocket for Interplanetary Propulsion", UCRL88857, Lawrence Livermore National Laboratory, Livermore, California, 1983.

12. C. Orth et. al., "Interplanetary Propulsion Using Inertial Fusion," Lawrence Livermore National Laboratory, Livermore, California, UCRL-95275 (1987)

13. H. C. Young, et.al., "Comparison of Boiler Feed Pumps for Cesium and Potassium Rankine Cycle Systems", Oak Ridge National Laboratory, Oak Ridge, Tenn., ORNL-TM-2086, September 1968. 
14. A. C. Marsha11, "RSMASS: A Preliminary Reactor/Shield Mass Model for SDI Applications", Sandia National Laboratory, Albuquerque, NM, SAND86-1020 August 1986.

15. J. C. Moyers and J. P. Nichols, "ALKASYS, A Computer Program for Studies of Rankine-Cycle Space Nuclear Power Systems," Oak Ridge National Laboratory, Oak Ridge, TN, ORNL-TM-10427, September 1987. 


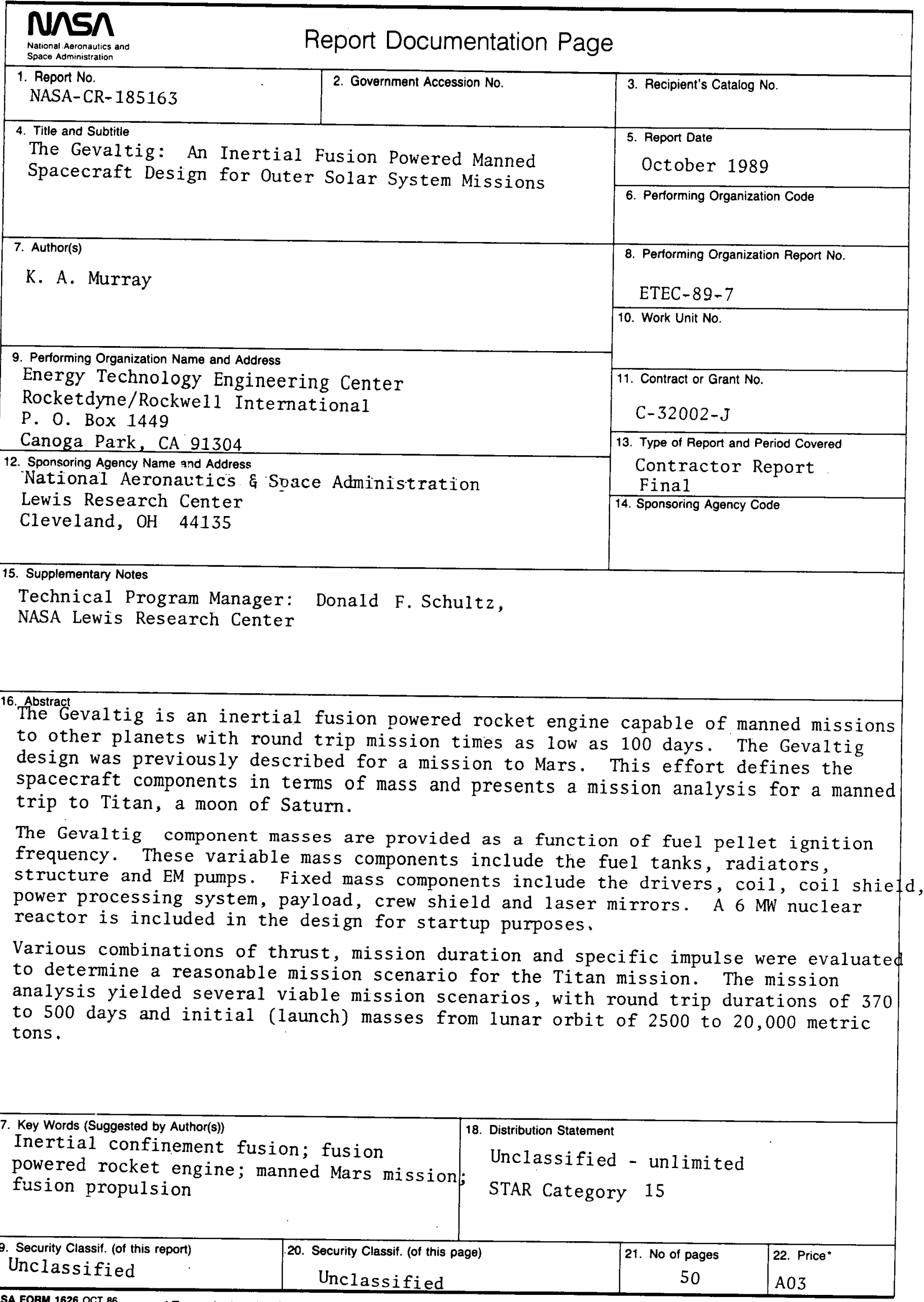

